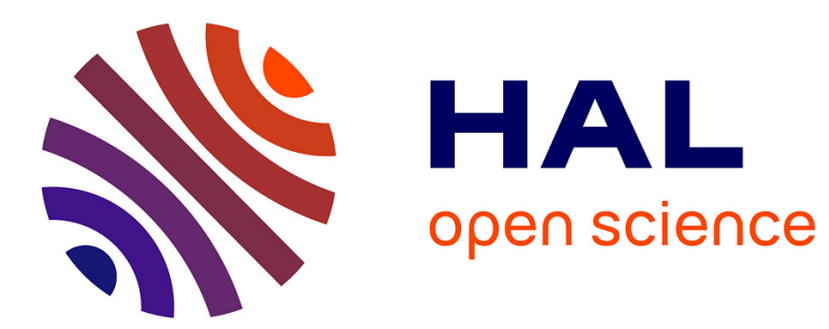

\title{
La nouvelle instrumentation de la politique agricole commune
}

\author{
Herve Guyomard, Louis Pascal Mahe
}

\section{To cite this version:}

Herve Guyomard, Louis Pascal Mahe. La nouvelle instrumentation de la politique agricole commune. 1994, 28 p. hal-01601253

\section{HAL Id: hal-01601253 \\ https://hal.science/hal-01601253}

Submitted on 2 Oct 2017

HAL is a multi-disciplinary open access archive for the deposit and dissemination of scientific research documents, whether they are published or not. The documents may come from teaching and research institutions in France or abroad, or from public or private research centers.
L'archive ouverte pluridisciplinaire HAL, est destinée au dépôt et à la diffusion de documents scientifiques de niveau recherche, publiés ou non, émanant des établissements d'enseignement et de recherche français ou étrangers, des laboratoires publics ou privés.

\section{(이) $\$$}

Distributed under a Creative Commons Attribution - NonCommercial - NoDerivatives| 4.0 


\section{LA NOUVELLE INSTRUMENTATION DE LA POLITIQUE AGRICOLE COMMUNE}

Hervé GUYOMARD* et Louis-Pascal MAHE* 


\section{La nouvelle instrumentation de la Politique Agricole Commune ${ }^{1}$}

Hervé Guyomard et Louis-Pascal Mahé

ENSA de Rennes et INRA-ESR, Unité PAM, Rennes

65 , rue de Saint-Brieuc

35042 Rennes cedex

Décembre 1993, révision Mars 1994

\section{Introduction}

La réforme de la Politique Agricole Commune (PAC) adoptée en mai 1992 par le Conseil des ministres des Communautés Européennes aborde, dans un souci de cohérence interne, les problèmes du secteur agricole de façon globale. La réforme est cependant centrée sur les oléoprotéagineux et les céréales car ces productions sont au coeur des problèmes de la PAC par la place qu'elles occupent dans l'occupation du sol, la production finale, les échanges, les dépenses budgétaires et les interactions végétal-animal par l'intermédiaire de l'alimentation animale.

Le prix des céréales, produit de base à transformer, devait être abaissé sous peine de fermer encore plus le marché communautaire, notamment celui de l'alimentation animale, et d'accroître les dépenses de restitutions sur pays tiers. Cette baisse des prix, compensée par un système d'aides forfaitaires à l'hectare, doit inciter les producteurs à utiliser des techniques culturales moins intensives, stabiliser les rendements puis ralentir leur taux de croissance. A court terme, la réduction de l'offre doit résulter surtout du gel des terres requis pour bénéficier des aides compensatrices sur les surfaces cultivées. Au total, maîtrise de l'offre et augmentation de la demande intérieure par amélioration de la compétitivité prix doivent donc réduire le déséquilibre du marché communautaire des céréales et rendre la PAC moins inacceptable pour nos concurrents internationaux.

La réforme de la PAC ne supprime donc pas le soutien, mais remplace - pour une large part l'aide aux produits par des aides liées aux facteurs et aux structures de production ${ }^{2}$. En d'autres termes, la réforme diminue le soutien par les prix et accroît le soutien par le budget ${ }^{3}$. Les nouvelles aides sont un enjeu économique important selon au moins trois points de vue, a) la compatibilité avec

1 Les auteurs remercient M. Baudry et A. Carpentier pour les discussions et leurs apports sur différents points. Ils remercient également R. Bourel, A.-M. Cardou, N. Hérrard et T. Trochet.

2 Dans le cas de la viande bovine et ovine, les aides sont basées sur les effectifs.

3 Burrell (1993) examine comment les mesures de soutien direct des revenus agricoles peuvent "faciliter" les réformes des politiques agricoles dans les pays de l'OCDE (Organisation de Coopération et de Développement Economique). Hulot (1993) présente, de manière claire, la mise en oeuvre pratique de la réforme de la PAC et, en particulier, des aides compensatrices. 
le GATT (General Agreement on Tariffs and Trade), et notamment l'accord final de décembre 1993, b) le soutien et la redistribution des revenus et, c) les conséquences sur l'allocation des ressources et l'environnement (en relation avec le gel des terres).

a) Les aides de la réforme ne sont pas conformes à la lettre du compromis Dunkel de décembre 1991 au GATT qui retient une définition restrictive de la boite verte. Le pré-accord de BlairHouse de décembre 1992 entre les Etats-Unis et l'Union Européenne et l'accord final de Bruxelles de décembre 1993 rendent cette difficulté caduque puisque les aides prévues par la réforme sont explicitement admises.

b) Les conséquences des aides ciblées sur la répartition individuelle des revenus ne seront pas examinées (sur ce point voir, par exemple, Josling et Mariani, 1991). Notons seulement que les nouvelles aides prévues dans la réforme ne seront guère moins régressives que le soutien de prix, bien que l'une des prémisses de la réforme ait été le constat que la PAC "pré-réformée", basée sur le soutien des prix, était particulièrement inégalitaire. Seule la répartition factorielle des revenus sera analysée dans cet article en soulignant le contraste entre le traitement réservé au facteur travail et celui accordé au capital de production (foncier essentiellement).

c) C'est donc l'impact de la réforme sur la combinaison productive, l'intensification et les rémunérations factorielles qui fait l'objet de cet article. Les limites des nouveaux instruments sont soulignées en faisant apparaître que les incitations créées par ces derniers ne sont pas toujours cohérentes avec les objectifs déclarés, c'est-à-dire une agriculture européenne plus compétitive et plus respectueuse de l'environnement.

Mahé et Rainelli (1987) ont clairement illustré la contradiction qu'il y avait, dans la PAC "préréformée", entre le soutien des prix et l'intensification d'une part, et le soutien des revenus du travail agricole et la préservation de l'environnement d'autre part. Plus précisément, ils ont montré que la fixité du facteur terre conduisait à une augmentation du prix de cet input et à un accroissement de l'intensification, définie ici simplement comme le rapport entre le travail, le capital et les consommations intermédiaires d'une part, et la terre d'autre part. Ils ont ensuite montré que le soutien des prix agricoles aggravait ces deux tendances et qu'il n'était qu'une médiocre politique d'aide au revenu du travail agricole dans la mesure où une grande partie de ce soutien était dissipée dans la rente foncière. Cette intensification a des conséquences négatives sur l'environnement qui résultent d'un écart croissant entre le niveau d'intensification optimal d'un point de vue individuel (dicté par les prix élevés) et le niveau d'intensification optimal du point de vue de la collectivité qui prend en compte, outre les coûts privés, les coûts publics des dommages. Il importe aujourd'hui d'examiner dans quelle mesure la nouvelle instrumentation de la PAC apporte des éléments de solution à ces problèmes.

Les effets des divers instruments de la réforme de la PAC (baisse des prix agricoles, gel des surfaces et aides compensatrices) sur l'offre du produit, les demandes de facteurs, l'intensification et 
les rémunérations factorielles sont analysés dans la Section 2 en utilisant la théorie du producteur entrepreneur dans le cadre simplifié d'une technologie mono-produit. Cette hypothèse est abandonnée dans la Section 3 où nous utilisons explicitement un modèle multi-produits qui permet de déterminer les fonctions d'allocation des surfaces et de décomposer l'impact sur l'offre des baisses des prix agricoles et des versements compensatoires de la réforme en un effet surface et en un effet rendement. Dans ce cadre multi-produits, nous montrons l'intérêt de supprimer le lien entre les aides compensatrices de la réforme et la terre, et de renforcer le lien entre les aides susceptibles d'encourager les externalités positives et le facteur foncier. La Section 4 s'affranchit du cadre analytique et tire quelques enseignements de l'étude théorique pour l'avenir de la Politique Agricole Commune. Nous émettons des réserves sur la conception et l'ampleur du gel actuel qui répond à la seule logique de réduction des surplus exportables. Un gel visant à promouvoir les fonctions de conservation de l'espace et des ressources devrait être encouragé. Les aides introduites par la réforme, destinées à compenser les pertes de revenu liées à la baisse des prix agricoles, devraient être transitoires et versées sous la forme de paiements directs détachés des facteurs de production, et notamment du foncier. En revanche, de nouvelles aides incitatrices liées plus directement aux objectifs publics de la politique agricole, tels que la préservation du milieu naturel, des valeurs esthétiques ou récréatives, etc., devraient être versées sous la forme de paiements permanents à l'hectare, paiements qui seraient modulés en fonction d'un zonage et de pratiques culturales génératrices d'aménités.

\section{Comportement d'offre du producteur agricole en présence d'aides ciblées et de facteurs rationnés}

On cherche à déterminer les effets nets des instruments de la réforme de la PAC (baisse des prix agricoles, gel des surfaces et aides directes) sur le comportement d'offre du producteur agricole, c'est-à-dire sur l'offre du produit, la demande des facteurs variables, l'intensification définie simplement comme le ratio inputs variables sur terre, et la rémunération des facteurs supposés fixes, terre et travail familial. On s'intéressera d'abord aux effets volumes globaux de mesures qui sont attachées aux facteurs de production (terre), puis à l'intensification sur les parcelles effectivement cultivées, et enfin à la rémunération des facteurs fixés à court-terme, terre et travail familial.

\subsection{Le cadre analytique}

L'analyse est appliquée au niveau de l'entreprise agricole en supposant que la terre et le travail familial sont fixes. C'est donc un horizon de court terme qui est considéré. La première hypothèse (terre fixe) est transposable à l'échelle de la branche dans le cas où l'offre globale de terre est supposée totalement inélastique. La seconde hypothèse (travail familial fixe) permet de se limiter au cadre de la théorie de la firme néoclassique et de s'affranchir des problèmes des structures et de mobilité sectorielle. De plus, on considère - dans un premier temps - le cas simplifié mono-produit. Les 
questions de l'allocation des surfaces entre productions et du découplage des aides compensatrices sont examinées dans la Section 3.

On considère d'abord le cas où il n'y a pas d'aides directes au revenu. Le programme de court terme du producteur agricole qui cherche à maximiser le revenu des facteurs supposés fixes, terre et travail familial, définit une fonction de profit restreint :

$$
\text { (1) } \pi^{r}(p, w, L, N)=\max _{y, x}[p y-w x ; y=f(x, L, N)]
$$

où $p$ représente le prix du produit $y, w$ le prix des facteurs variables agrégés dans $x, L$ la terre et $N$ le travail familial. Les prix du produit et des inputs variables sont exogènes. La fonction de production est notée $y=f(x, L, N)$ et $\pi^{r}(p, w, L, N)$ est la fonction de profit restreint, solution du programme (1).

Les fonctions d'offre du produit (équation (2a)) et de demande dérivée du facteur variable (équation (2b)) s'obtiennent par application directe du lemme de Hotelling. Les prix virtuels associés aux facteurs fixes sont égaux aux dérivées premières de la fonction de profit restreint par rapport aux quantités fixées (Lau, 1976) ${ }^{4}$.

$$
\begin{aligned}
& \text { (2a) } y(p, w, L, N)=\partial \pi^{r}(p, w, L, N) / \partial p \\
& \text { (2b) } x(p, w, L, N)=-\partial \pi^{r}(p, w, L, N) / \partial w \\
& \text { (2c) } \lambda(p, w, L, N)=\partial \pi^{r}(p, w, L, N) / \partial L \\
& \text { (2d) } \eta(p, w, L, N)=\partial \pi^{r}(p, w, L, N) / \partial N
\end{aligned}
$$

où $\lambda(p, w, L, N)$ est le prix virtuel de la terre et $\eta(p, w, L, N)$ le prix virtuel du travail familial.

On définit ensuite la fonction de profit virtuel $\pi(p, w, \lambda, N)$, qui correspond au profit effectif (rémunération du travail familial) si la terre était rémunérée à son prix virtuel défini par $(2 \mathrm{c})$, par l'identité suivante :

(3) $\pi(p, w, \lambda, N)=\pi^{r}(p, w, L, N)-\lambda L$

$\operatorname{avec} \lambda(p, w, L, N)=\partial \pi^{r}(p, w, L, N) / \partial L$

La dérivée première de la fonction de profit virtuel par rapport au prix virtuel de la terre est égale à la quantité fixée de terre (au signe près). Cette dernière correspond à la surface qu'il serait optimal de cultiver si le prix de la terre était en réalité le prix fictif $\lambda$.

4 Dans le cas simplifié où il n'y a pas de facteur variable, le prix virtuel d'un input représente simplement la productivité marginale en valeur de ce dernier. 
(4) $\partial \pi(p, w, \lambda, N) / \partial \lambda=-L$

L'offre du produit et la demande du facteur variable peuvent donc également s'écrire en termes de dérivées premières de la fonction de profit virtuel :

(5a) $\partial \pi(p, w, \lambda, N) / \partial p=y(p, w, \lambda(p, w, L, N), N)=y(p, w, L, N)$

(5b) $\partial \pi(p, w, \lambda, N) / \partial w=-x(p, w, \lambda(p, w, L, N), N)=-x(p, w, L, N)$

On examine maintenant les conséquences de l'introduction du gel des surfaces et des aides compensatrices à l'hectare. Le programme de court terme du producteur agricole s'écrit alors :

$$
\begin{aligned}
\pi^{a}(p, w, L-G, N, a, g, G) & =\max _{y, x}[p y-w x ; y=f(x, L-G, N)]+a(L-G)+g G \\
& =\pi^{r}(p, w, L-G, N)+a(L-G)+g G
\end{aligned}
$$

où a représente l'aide compensatrice à l'hectare, aide unitaire basée sur des rendements moyens passés et non sur les rendements individuels du producteur considéré, $g$ l'aide compensatrice par hectare gelé et $G$ la surface gelée. $L$ représente toujours la surface totale disponible. Les aides étant conditionnelles au gel, la seconde ligne de (6a) suppose que les aides a et $g$ sont assez élevées pour exclure le cas où le gel ne serait plus profitable ${ }^{5}$.

Le comportement du producteur agricole dans la PAC réformée peut donc être résumé par la maximisation du profit restreint, c'est-à-dire par la maximisation de la rémunération des facteurs fixes, terre cultivée $L-G$ et travail familial $N$. Les aides, sur les surfaces cultivées et gelées, n'interviennent dans le programme (6a) que comme compléments de revenu. Néanmoins ces aides, même dans le cadre mono-produit considéré ici, ne sont pas strictement découplées. Les aides sur les surfaces cultivées ne sont en effet payées sur la base primable $L-G$ que dans la mesure où celle-ci est cultivée. Si cette condition n'était pas imposée, l'agriculteur ne cultiverait pas si le rapport du prix du produit aux prix des facteurs variables $p / w$ devenait assez faible pour conduire à un profit restreint négatif $\left(\pi^{r}(p, w, L-G, N)<0\right)$. Dans le cadre de la législation actuelle, ce revenu " hors primes " peut être négatif et les hectares correspondants néanmoins cultivés si les aides a et $g$ sont assez élevées. Ce résultat révèle la contradiction entre l'objectif de réduction des surplus exportables et la conditionnalité des aides à la culture des surfaces $L-G$ et à l'entretien de la jachère $G$. L'absence de découplage des aides est encore plus net dans le cadre multi-produits dans la mesure où les aides ont un effet sur l'allocation des surfaces. Ce point est détaillé dans la Section 3.

Alternativement, le programme (6a) peut s'écrire sur la base de la fonction de profit virtuel :

5 Il en est ainsi quand $\pi^{r}(p, w, L, N)>\pi^{r}(p, w, L-G, N)+a(L-G)+g G$. Cette inégalité est naturellement vérifiée pour $a=g=0$, et plus généralement quand les aides sont faibles. 
(6b) $\pi^{a}(p, w, L-G, N, a, g, G)=\pi(p, w, \lambda, N)+(\lambda+a)(L-G)+g G$

$\operatorname{avec} \lambda(p, w, L-G, N)=\partial \pi^{r}(p, w, L-G, N) / \partial L$.

Les effets des mesures de la réforme de la PAC sont donc analysés sur la base du programme (6a) défini à partir de la fonction de profit restreint ou, de manière équivalente, en utilisant le programme (6b) défini à l'aide de la fonction de profit virtuel. La second programme (6b) permet, en particulier, de décomposer les effets des instruments en un effet direct et en un effet indirect qui passe par l'intermédiaire du prix virtuel de la terre, facteur rationné par le gel des surfaces.

Afin d'identifier les effets des divers instruments, on analyse dans un premier temps les conséquences de la baisse du prix du produit et du gel des surfaces. Les effets de l'introduction de versements compensatoires sont examinés dans une deuxième étape. On rappelle que les prix des facteurs variables sont donnés et que la quantité de travail familial ne varie pas.

\subsection{Effets de la baisse du prix et du gel des surfaces}

i) impact sur l'offre du produit et la demande du facteur variable

Les impacts de la baisse du prix du produit et du gel des surfaces sur l'offre du produit et la demande du facteur variable s'obtiennent par différentiation totale de (2a) et de (2b), respectivement.

(7a) $d y=\pi_{p p}^{r} d p+\pi_{p L}^{r} d L$

(7b) $d x=-\pi_{w p}^{r} d p-\pi_{w L}^{r} d L$

L'équation (7a) montre que la baisse du prix va faire diminuer l'offre du produit et l'équation (7b) montre que la baisse du prix va également faire diminuer la demande du facteur variable car ce dernier, agrégat des différents facteurs variables, ne peut pas être un input inférieur ${ }^{6}$. Les effets du gel sur l'offre du produit et la demande du facteur variable sont résumés par les termes $\pi_{p L}^{r}$ et $\pi_{w L}^{r}$, respectivement.

Alternativement, et de façon peut-être plus transparente, les équations (7a) et (7b) peuvent s'écrire en termes de dérivées secondes de la fonction de profit virtuel. Par différentiation totale de (5a) et de $(5 b)$, on $a$ :

(8a) $d y=\pi_{p p} d p+\pi_{p \lambda} d \lambda$

6 La fonction de demande dérivée du facteur variable est homogène de degré 0 par rapport aux prix $\mathrm{p}$ et $\mathrm{w}$ $\left(\pi_{w w}^{r} w+\pi_{w p}^{r} p=0\right)$. La fonction de profit restreint étant convexe par rapport aux prix, on a aussi $\pi_{w w}^{r}>0$. Par suite, $\pi_{w p}^{r}<0$. 
(8b) $d x=-\pi_{w p} d p-\pi_{w \lambda} d \lambda$

L'équation (4), après différenciation et résolution en $\lambda$, permet de déterminer les effets de la baisse des prix agricoles et du gel des surfaces sur le prix virtuel de la terre :

(9) $d \lambda=\left(\pi_{\lambda \lambda}\right)^{-1}\left(-d L-\pi_{\lambda p} d p\right)$

On obtient alors, en utilisant (9) dans (8a) et (8b), une expression de la variation de l'offre du produit et de la demande dérivée du facteur variable équivalente aux relations (7):

$$
\begin{aligned}
& \text { (10a) } d y=\left(\pi_{p p}-\pi_{p \lambda}\left(\pi_{\lambda \lambda}\right)^{-1} \pi_{\lambda p}\right) d p-\pi_{p \lambda}\left(\pi_{\lambda \lambda}\right)^{-1} d L \\
& \text { (10b) } d x=-\left(\pi_{w p}-\pi_{w \lambda}\left(\pi_{\lambda \lambda}\right)^{-1} \pi_{\lambda p}\right) d p+\pi_{w \lambda}\left(\pi_{\lambda \lambda}\right)^{-1} d L
\end{aligned}
$$

Le premier terme du membre de droite de (10a) est négatif car la fonction de profit virtuel est convexe par rapport aux prix et la variation du prix du produit est négative ${ }^{7}$. La comparaison de (7a) et de (10a) montre que le rationnement du facteur foncier a tendance à atténuer l'effet négatif direct de la baisse du prix sur l'offre du produit (effet Le Chatelier-Samuelson). Le second terme du membre de droite de (10a) est également négatif si la terre est un input normal (non inférieur) ${ }^{8}$.

La baisse seule du prix du produit (c'est-à-dire quand $d L=0$ ) a deux effets sur la demande du facteur variable (équation (10b)), i) un effet direct négatif (le facteur variable est normal) et, ii) un effet indirect lié à la baisse induite du prix virtuel de la terre. L'effet indirect est négatif si la terre et le facteur variable sont substituts $\left(\pi_{w \lambda}<0\right)$ et positif si les deux inputs sont compléments $\left(\pi_{w \lambda}>0\right)$, la terre étant supposée facteur normal $\left(\pi_{\lambda p}<0\right)$. L'effet du gel des terres est représenté par le second terme du membre de droite de (10b) : il est positif si la terre et le facteur variable sont substituts, négatif si les deux inputs sont compléments. L'effet indirect de la baisse du prix du produit dû à la contrainte foncière et l'effet du gel des terres sont donc toujours de signes opposés.

\section{ii) impact sur le prix (virtuel) de la terre et l'intensification}

L'impact de la baisse du prix et du gel sur l'intensification des terres cultivées peut être étudié en comparant la variation de la demande du facteur variable (équations (7b) ou (10b)) à la variation de la surface, qui est nulle si il n'y a pas d'obligation de gel et égale à $-G$ en cas de gel.

S'il n'y a pas de gel des surfaces, la diminution du prix du produit entraîne, sans ambiguïté, une baisse de la demande du facteur variable (cf. Equation (7b)). L'extensification est alors certaine : à

7 Le Hessien de la fonction de profit virtuel est défini non négatif. Le premier terme de droite entre parenthèses de (10a) a le signe d'un mineur principal du Hessien de la fonction de profit virtuel et est donc positif.

8 Dans ce cas, $\pi_{p \lambda}$ est négatif. $\pi_{\lambda,}$ étant positif et $d L$ négatif, le second terme du membre de droite de (10a) est donc négatif. 
surface fixée, le rapport facteur variable sur terre diminue. De plus, la relation (9) montre alors que le prix des terres baisse si on suppose que la terre est un facteur normal.

Quand une partie des surfaces est gelée, l'impact de la baisse du prix de soutien et du gel sur le prix de la terre est ambigu. Ce dernier a tendance à augmenter sous l'effet du gel et à diminuer sous l'effet de la baisse du prix de soutien. L'effet total dépend naturellement de l'ampleur de la baisse du prix de soutien et du gel, et des paramètres de la fonction de demande de terre. L'équation (9) peut s'écrire en termes d'élasticités :

$$
\text { (11) } \hat{\lambda}=\left(\varepsilon_{\lambda \lambda}\right)^{-1}\left(\hat{L}-\varepsilon_{\lambda p} \hat{p}\right)
$$

où un "chapeau" représente la variation relative de la variable considérée, $\varepsilon_{2, \lambda}$ l'élasticité prix propre de la demande de terre et $\varepsilon_{\lambda p}$ l'élasticité prix croisée de la demande de terre par rapport au prix du produit.

Dans le cadre de la réforme de la PAC, le rapport $(\hat{L} / \hat{p})$ est de l'ordre de 0,5 et le prix virtuel de la terre diminue (respectivement augmente) si l'élasticité de la demande de terre par rapport aux prix agricoles est supérieure (inférieure) à 0.5. Dans le cas des exploitations céréalières de l'OTEX 11, l'élasticité prix propre de la demande de terre a été estimée à -0,31 et l'élasticité de la demande de terre par rapport au prix des céréales à 1,39 (élasticités calculées au point moyen, à niveau de travail familial fixe, Guyomard et Vermersch, 1989). En supposant que le gel des surfaces est égal à $15 \%$ et la baisse du prix du produit à $30 \%$, la baisse du prix virtuel de la terre est alors égale à $-86,8 \%$ (c'està-dire, 0,49-1,35). Le gel des surfaces, en zones céréalières spécialisées, semble donc en mesure de compenser pour un tiers environ la baisse du prix de la terre due à la diminution du prix de soutien des céréales.

Sur la demande du facteur variable, et dans l'hypothèse où ce dernier est un substitut de la terre, il n'est donc pas impossible que le gel des terres compense l'effet indirect d'extensification dû à la baisse du prix virtuel de la terre elle-même liée à la baisse du prix du produit. Mais il est difficile d'envisager que l'effet du gel surcompense les effets négatifs, direct et indirect, de la baisse du prix du produit. La demande du facteur variable devrait donc diminuer et l'extensification globale (c'est-à-dire sur toutes les surfaces) est probable. En cas de complémentarité, le gel renforce l'effet direct d'extensification et celle-ci est donc également vraisemblable avec les ordres de grandeur actuels du gel et les élasticités estimées.

L'intensification sur les terres cultivées (rapport facteur variable sur surfaces effectivement cultivées) va diminuer si la variation relative de la demande du facteur variable est, en valeur absolue, supérieure au pourcentage de terres gelées. L'extensification sur les surfaces cultivées aura donc lieu si l'expression suivante est négative :

(12a) $\hat{x}-\hat{L}=\left[\varepsilon_{w p}-\varepsilon_{w \lambda}\left(\varepsilon_{\lambda \lambda}\right)^{-1} \varepsilon_{\lambda p}\right] \hat{p}+\left[\varepsilon_{w \lambda}\left(\varepsilon_{\lambda \lambda}\right)^{-1}\right] \hat{L}-\hat{L}$ 
ou, de manière équivalente ${ }^{9}$,

(12b) $\hat{x}-\hat{L}=\varepsilon_{w p}^{r} \hat{p}+\left(\varepsilon_{w L}^{r}-1\right) \hat{L}$

en définissant les élasticités "restreintes", prix et quantité, sur la base de la fonction de profit restreint.

Finalement, il y aura donc extensification si :

(12c) $\varepsilon_{w p}^{r} \geq \frac{\left(1-\varepsilon_{w L}^{r}\right) \hat{L}}{\hat{p}}$

Cette condition est vraisemblablement satisfaite avec les paramètres de la réforme actuelle. Elle sera d'autant plus facile à satisfaire que, i) l'élasticité (restreinte) de la demande du facteur variable par rapport aux prix agricoles est positive et élevée, ii) l'élasticité (restreinte) de la demande du facteur variable par rapport à la quantité de terre est positive et élevée (facteurs complémentaires), iii) la baisse des prix agricoles est importante, et iv) le taux de gel des surfaces est faible. Seuls une forte substituabilité entre la terre et les facteurs variables et un gel des terres important relativement à la baisse du prix du produit peuvent remettre en cause l'extensification des terres cultivées.

\subsection{Prise en compte des aides compensatrices}

\section{i) impact des versements compensatoires sur l'offre et la demande dérivée}

Les variations de l'offre du produit et de la demande du facteur variable engendrées par les instruments de la réforme - variation du prix du produit, gel des surfaces et aides compensatrices à l'hectare - sont toujours définies par les équations (10a) et (10b), respectivement, dans la mesure où le comportement du producteur est représenté par le programme (6b). Ces équations s'obtiennent par différenciation au deuxième ordre de $(6 \mathrm{~b})$. Les versements compensatoires de la réforme n'ont pas d'impact sur l'offre du produit et sur la demande du facteur variable, dans le cas d'une technologie mono-produit, lorsque la terre est contrainte ${ }^{10}$ et lorsque les aides à l'hectare sont découplées des rendements effectifs.

\section{ii) impact sur l'intensification}

9 Le premier terme entre crochets du membre de droite de (12a) est l'élasticité restreinte de la demande du facteur variable par rapport aux prix agricoles, la terre étant contrainte. Le second terme entre crochets est l'élasticité restreinte de la demande du facteur variable par rapport à la terre. On en déduit l'expression (12b).

10 Et donc au niveau global si l'offre de terre est parfaitement rigide. Si l'offre de terre a une élasticité non nulle, une partie de l'aide est transférée aux propriétaires de la terre et une partie aux exploitants de cette dernière sous la forme d'une baisse des coûts (prix payé) pour l'utilisation des surfaces. L'expression (6b) montre clairement que l'offre du produit $(y=\partial \pi(p, w, \lambda, N) / \partial p)$ ne dépend pas de l'aide compensatrice $a$ puisque le prix virtuel de la terre $\lambda$ lui non plus ne dépend pas de $a$. Le même argument vaut pour la demande du facteur variable. 
Puisque les versements compensatoires n'ont pas d'impact sur la demande du facteur variable, on retrouve les conditions d'extensification (12). Le graphique 1 permet d'illustrer la décomposition des effets de la réforme sur le rapport facteur variable - terre cultivée. La situation initiale correspond au point $A$, où la pente de la tangente à l'isoquante de production est égale au rapport du prix virtuel de la terre au prix du facteur variable. L'effet de la baisse du prix conduit du point $A$ au point $B$. La demande du facteur variable diminue, de $x_{0}$ à $x_{1}$, sous les effets, direct et indirect, de la baisse du prix du produit (cf. équation (10b)). Le prix virtuel, c'est-à-dire le coût d'opportunité de la terre, diminue également $\left(\lambda_{1}<\lambda_{0}\right)$, assurant le plein emploi de la terre (cf. équation (9)). Sans gel, il y a extensification certaine. Le gel d'une partie des surfaces atténue cette extensification et nous ramène au point $C$. La demande du facteur variable augmente de $x_{1}$ à $x_{2}$ (cas où la terre et le facteur variable sont substituts) et le prix virtuel de la terre augmente par rapport à la situation sans gel $\left(\lambda_{2}>\lambda_{1}\right)$. II est clair que l'extensification sur l'ensemble des surfaces (extensification mesurée par le rapport $x / L_{o}$ ) pourrait être effacée si le taux de gel était augmenté jusqu'au niveau $G_{I}$ de façon à ce que l'équilibre final se situe au point $D$ sur l'isoquante $y_{3}$. Ceci suppose que la terre et les facteurs variables soient "suffisamment" substituables pour que l'intensification sur les terres cultivées permette de produire au niveau $y_{3}$, proche du niveau $y_{2}$, en remplaçant facilement la terre par les différents facteurs variables dont, en particulier, les consommations intermédiaires.

(insérer Graphique 1)

L'aide à l'hectare n'a donc pas d'influence sur l'intensification dans la mesure où les surfaces primables sont fixées et ne peuvent être augmentées ${ }^{11}$.

A ce stade de l'analyse, il est intéressant de considérer à nouveau les conditions favorables à l'extensification, conditions résumées par (12). Si le prix perçu par le producteur n'est plus le prix de marché, mais la somme de ce dernier et de l'aide compensatrice moyenne à la tonne $b$ comme dans le cas d'une aide couplée, alors la variation relative du prix dans (12c) devrait être nulle ou faible et l'extensification nettement plus incertaine. Cette "perception" de l'aide est néanmoins improbable car les agriculteurs perçoivent $p$, et non $p+b$, pour les dernières quantités vendues. D'autre part, l'augmentation du nombre de fixités, sur les produits et les facteurs, a tendance à favoriser l'infériorité c'est-à-dire ici à décroître l'élasticité de la demande du facteur variable par rapport aux prix agricoles et la substitution - c'est-à-dire ici à décroître (en valeur algébrique) l'élasticité de la demande du facteur variable par rapport à la quantité de terre (Guyomard et Mahé, 1993). L'augmentation du nombre de contraintes quantitatives sur les produits et les facteurs rend donc l'extensification plus difficile. Enfin, il est clair qu'une augmentation du gel (dans le cadre, par exemple, de l'option gel fixe) ou une baisse plus faible du prix de soutien rendent l'extensification, sur les surfaces cultivées, plus improbable.

11 S'il était possible d'accroître les références primables en acquérant des terres, hors références céréales et oléoprotéagineux, les aides auraient un effet d'intensification sur les terres non primables à cause de leur renchérissement. 
Le tableau 1 résume les effets des trois instruments de la réforme sur la demande du facteur variable et sur l'intensification.

(insérer Tableau 1)

iii) prix virtuel et valeur de la terre

La valeur de la terre cultivée en présence d'aides compensatrices est égale à (par dérivation de (6b) par rapport à la terre) :

(13) $\partial \pi^{a}(p, w, L-G, N, a, g, G) / \partial L=\lambda+a=\varphi=\partial \pi^{r}(p, w, L-G, N) / \partial L+a$

La valeur de la terre cultivée est donc égale à la somme du prix virtuel $\lambda$ (rendement marginal en valeur) de cette dernière et de l'aide à l'hectare a. L'aide directe à l'hectare a donc un impact positif, égal à son montant, sur la valeur marchande de la terre dans la mesure où sa cession est accompagnée du droit aux primes. II est intéressant de noter que l'aide n'a pas d'impact sur le rendement marginal de la terre $\lambda$. L'offre du produit $y=\partial \pi^{a}(p, w, L-G, N, a, g, G) / \partial p=\partial \pi(p, w, \lambda, N) / w$ et la demande de facteur variable $x=-\partial \pi^{a}(p, w, L-G, N, a, g, G) / \partial w=-\partial \pi(p, w, \lambda, N) / \partial w$ ne dépendent que de ce prix virtuel $\lambda$, et non de la valeur marchande de la terre cultivée $\varphi=\lambda+a$.

Au total, la réforme de la PAC a donc, théoriquement, un effet ambigu sur la valeur de la terre. La baisse du prix du produit a tendance à diminuer le prix virtuel, mais le gel a tendance à augmenter ce dernier. Les versements compensatoires ont pour effet d'accroître la valeur marchande de la terre du montant de leur valeur. II est vraisemblable que les deux derniers composants surcompensent l'effet négatif de la baisse du prix du produit sur la valeur de la terre. Cette situation est illustrée par le graphique 2. L'équilibre initial correspond au point A (terre $L_{0}$, rendement marginal du facteur terre $\lambda_{0}$, prix virtuel de la terre $\lambda_{0}$, valeur de la terre $\lambda_{0}$ ). La baisse du prix du produit réduit le rendement marginal de la terre de $\lambda_{0}$ à $\lambda_{1}$. Le gel d'une partie des surfaces, de $L_{0}$ à $L_{2}=L_{0}-G$, augmente le rendement marginal de la terre de $\lambda_{1}$ à $\lambda_{2}$. Enfin, l'aide compensatrice laisse inchangé le prix virtuel de la terre cultivée à $\lambda_{2}$, mais augmente la valeur marchande de la terre (pour le propriétaire du droit aux primes) du montant de l'aide compensatrice à l'hectare, c'est-à-dire a. Au total, sur cet exemple, la valeur de la terre augmente passant de $\varphi_{0}=\lambda_{1}$ à $\varphi_{3}=\lambda_{2}+a$.

(insérer Graphique 2)

\section{iv) rémunération de la terre et du travail familial}

Les aides étant calculées sur des rendements forfaitaires antérieurs à la baisse de prix, on montre, en premier lieu, que la perte de revenu sur les surfaces cultivées est « surcompensée " pour l'agriculteur moyen. 
Proposition. Le profit restreint sur les terres effectivement cultivées, compensé avec les rendements ex-ante, ne peut être inférieur au profit restreint avant baisse de prix.

La compensation est basée sur la baisse de prix $b$ appliquée à la production ex-ante. Elle est donc égale à :

(P.1) $b y(p+b, w, L-G, N)=a(L-G)$

où $p$ représente le prix après réforme.

Il y aura donc surcompensation sur les surfaces cultivées si la somme du profit restreint évalué avec le nouveau prix de soutien et de la compensation est supérieure ou égale au profit restreint calculé avec l'ancien prix de soutien, c'est-à-dire si :

$$
\text { (P.2) } \pi^{r}(p, w, L-G, N)+b y(p+b, w, L-G, N) \geq \pi^{r}(p+b, w, L-G, N)
$$

L'inégalité (P.2) est vérifiée parce que la fonction de profit restreint est convexe par rapport aux prix. On a donc :

$$
\begin{aligned}
\pi^{r}(p, w, L-G, N) & \geq \pi^{r}(p+b, w, L-G, N)+(p-p-b) \partial \pi^{r}(p+b, w, L-G, N) / \partial p \\
= & \pi^{r}(p+b, w, L-G, N)-b y(p+b, w, L-G, N)
\end{aligned}
$$

(P.3) établit la proposition qui trouve sa justification dans le fait que les agriculteurs peuvent ajuster leurs techniques d'intensification aux nouveaux rapports de prix et que, par suite, la variation de revenu n'est pas linéaire par rapport aux prix.

Les variations dues à la réforme des valeurs des deux facteurs fixes, terre et travail familial, sont données par les équations suivantes (équations déduites de (2c) et (2d), respectivement) :

(14a) $d \varphi=d \lambda+d a=\pi_{L p}^{r} d p+\pi_{L L}^{r} d L+d a$

(14b) $d \eta=\pi_{N p}^{r} d p+\pi_{N L}^{r} d L$

II apparaît que l'aide compensatrice contribue à accroître la valeur de la terre, c'est-à-dire la rente foncière, mais qu'elle n'a aucun impact sur le prix virtuel du travail familial qui est égal à sa valeur marginale. La baisse du prix du produit a un impact négatif sur la valeur des deux facteurs si la terre et le travail familial sont des inputs normaux, hypothèse plausible. Le gel des surfaces a un impact positif sur le prix (virtuel), et donc sur la valeur, de la terre et un effet ambigu sur le prix virtuel du travail familial (cet effet dépend des relations de substitution-complémentarité entre les deux facteurs primaires). 
Les variations des rémunérations totales implicites de la terre (cultivée) et du travail familial induites par la réforme sont données par les seuls effets des prix virtuels et des aides compensatrices à l'hectare puisque les quantités de facteurs sont fixées aux niveau $L-G$ et $N$.

(15a) $d W_{L}=(L-G) d \varphi$

(15b) $d W_{N}=N d \eta$

Le profit restreint rémunère les deux facteurs supposés fixes, terre et travail familial, et les prix viriuels constituent la base optimale de l'affectation du revenu à ces deux inputs compte tenu de leurs valeurs d'opportunité. II est clair que pour un agriculteur propriétaire, c'est le reliquat global disponible pour les deux facteurs fixes qui importe. Les équations (15a) et (15b) ne sont qu'un guide de l'allocation optimale des ressources terre et travail sur et hors de l'exploitation.

Dans le cas d'un "petit" agriculteur qui n'a pas d'obligation de gel, le prix virtuel du travail familial diminue. Le prix virtuel de la terre diminue également sous l'effet de la baisse des prix. L'aide compensatrice atténue la perte de valeur de la terre puisqu'elle vient s'ajouter au prix virtuel pour déterminer la valeur. La part de la terre dans le profit restreint a donc tendance à croître, celle du travail à diminuer.

Dans le cas d'un producteur "professionnel" qui a obligation de geler une partie des surfaces, l'impact du gel sur le prix virtuel du travail familial est positif si la terre et le travail familial sont substituables. Néanmoins, il est vraisemblable que l'impact négatif de la baisse des prix est plus important, en valeur absolue, que l'impact positif du gel. Au total, le prix virtuel du travail familial devrait donc diminuer plus fortement que la valeur de la terre à cause de l'aide et parce que l'effet du gel sur le prix virtuel de la terre (effet propre) est, en général, plus fort que l'effet croisé sur le prix virtuel du travail familial. La part de la terre dans le revenu total des facteurs fixes, terre et travail familial, devrait donc également augmenter, sauf si la demande de terre est très élastique (faible incidence du gel sur le prix virtuel de la terre) et si le gel est important et compensé pour un montant inférieur au prix virtuel initial de la terre.

L'analyse précédente est illustrée par les graphiques 3.1 et 3.2. Le graphique 3.1 permet d'analyser la variation du prix virtuel et de la rémunération de la terre. Sous l'effet de la réforme, le rendement marginal en valeur (c'est-à-dire le prix virtuel) de la terre diminue de $\lambda_{0}$ à $\lambda_{2}$, mais la valeur de la terre cultivée augmente de $\varphi_{0}=\lambda_{0}$ à $\varphi_{3}$, où $\varphi_{3}$ est égal à la somme du prix virtuel $\lambda_{2}$ et de l'aide à l'hectare $a$. La variation de la rémunération de la surface cultivée est positive et égale à l'aire hachurée $A B C D$, différence entre la surface $A B E F$ qui représente les aides et la surface $C D E F$ qui mesure la baisse de la rémunération virtuelle des surfaces cultivées. Le graphique 3.2 permet d'étudier la variation du prix virtuel (égal à la rémunération) du travail familial, supposé fixe au niveau $N_{0}$. Le prix du travail familial avant réforme est égal à $\eta_{0}$. La baisse du prix du produit fait baisser le 
prix virtuel du travail familial de $\eta_{0}$ à $\eta_{l}$. Le gel d'une partie des surfaces (ou, de manière équivalente, l'augmentation du prix virtuel de la terre induit par le gel) fait croître le prix virtuel du travail familial si la terre et le travail familial sont des facteurs substituts $\left(\eta\right.$ passe de $\eta_{1}$ à $\eta_{2}$ ). La variation totale de la rémunération virtuelle du travail familial est - vraisemblablement ${ }^{12}$ - négative et égale à la surface $A B C D$.

(insérer Graphiques 3.1 et 3.2)

\section{Le cas multi-produits et le difficile découplage des aides}

i) le problème de l'allocation des surfaces

Dans le cas d'un seul produit et d'aides basées sur un stock de facteurs de référence fixé (ici les surfaces), les aides compensatrices à l'hectare peuvent être considérées comme découplées dans la mesure où elles n'affectent pas le prix virtuel de la terre ${ }^{13}$. Il en est autrement dans le cas multiproduits si les aides diffèrent d'une culture à l'autre à l'intérieur d'une sole globale primable.

On part d'une présentation générale du problème afin de faire apparaître les variables clés de l'impact des aides sur l'allocation. On s'intéresse ensuite au cas particulier de la réforme.

Afin de simplifier la présentation, on considère le cas de deux cultures, primables aux taux respectifs $a_{1}$ et $a_{2}$, pour une sole globale fixe $L$ et une quantité de main d'oeuvre familiale fixe $N$. On suppose que les deux cultures ne sont jointes que par leur compétition dans l'allocation des facteurs allouables, terre et travail, c'est-à-dire que la technologie est non jointe par rapport aux facteurs variables (Kohli, 1981). Le problème du producteur s'écrit alors :

(16) $\underset{L_{1}, L_{2}, N_{1}, N_{2}}{\operatorname{Max}}\left[\pi^{1}\left(p_{1}, w, L_{1}, N_{1}\right)+a_{1} L_{1}+\pi^{2}\left(p_{2}, w, L_{2}, N_{2}\right)+a_{2} L_{2} ; N_{1}+N_{2}=N ; L_{1}+L_{2}=L\right]$ avec :

(17) $\pi^{i}\left(p_{i}, w, L_{i}, N_{i}\right)=\operatorname{Max}_{y_{i}, x_{i}}\left[p_{i} y_{i}-w x_{i} ; y_{i}=f\left(x_{i}, L_{i}, N_{i}\right)\right] \quad i=1,2$

Les conditions du premier ordre du programme (16) déterminent, de manière implicite, les quantités optimales de terre et de travail allouées à chaque culture, étant donné les contraintes de disponibilité globale.

(18a) $\pi_{L}^{1}+a_{1}=\pi_{L}^{2}+a_{2} ; L_{1}+L_{2}=L$

12 Sauf si le gel est très important et l'effet croisé du prix de la terre sur la demande de travail très élevé.

13 Dans la mesure où les aides compensatrices sont conditionnelles au gel des terres qui lui affecte le prix virtuel, elles ne sont pas strictement découplées, même dans le cas mono-produit. 
(18b) $\pi_{N}^{1}=\pi_{N}^{2} ; N_{1}+N_{2}=N$

Les conditions (18a) et (18b) font clairement apparaître le contraste entre l'effet des aides sur l'allocation des surfaces et l'effet de ces aides sur l'affectation du travail. Alors que l'allocation du travail entre les deux cultures n'est guidée que par les rendements marginaux du travail (c'est-à-dire par les prix virtuels), celle de la terre est fonction des aides. Le graphique 4.1 illustre l'allocation de la terre. Les droites de rendements marginaux en valeur ( $D_{l}^{l}$ pour la surface consacrée à la première culture, $D_{2}^{I}$ pour la surface consacrée à la seconde culture) reflètent la situation après réforme, sans aides. On se situe alors au point $B$. Le fait que l'aide compensatrice sur la surface en culture 1 soit plus élevée que l'aide sur la surface cultivée en produit 2 conduit l'agriculteur à choisir l'allocation $A$ au lieu de l'allocation $B$, et donc à accroître la surface allouée à la première culture de $O_{1} M_{0}$ à $O_{1} M_{1}$. L'allocation $A$ engendre une inefficacité liée à l'écart des productivités marginales en valeur des deux surfaces au point $A$ (longueur $M E$ > longueur $M F$ ) et une charge morte mesurée par l'aire $B E F$, surface d'autant plus importante que l'écart entre les prix virtuels des surfaces allouées aux deux cultures est grand $\left(E F=\pi_{L}^{2}-\pi_{L}^{l}=a_{1}-a_{2}\right)$. Pour justifier le non découplage des aides, il faut donc que la valeur sociale relative à la valeur privée soit plus élevée pour le bien 1 que pour le bien 2 . Mais, même dans ce cas, la politique ne peut pas être de premier rang en raison de l'incohérence des incitations qui déterminent les allocations de la terre et du travail.

(insérer Graphique 4.1)

L'analyse graphique est confirmée analytiquement par l'étude de la statique comparative du système (18). Dans un premier temps, nous résolvons les conditions (18b) sur le travail, ce qui nous permet d'écrire les allocations de travail, $N_{1}$ et $N_{2}$, comme fonctions de la quantité totale de travail $N$. La condition (18a) s'écrit alors :

(19) $\pi_{L}^{1}\left(p_{1}, w, L_{1}, N\right)+a_{1}=\pi_{L}^{2}\left(p_{2}, w, L_{2}, N\right)+a_{2} ; L_{1}+L_{2}=L$

On suppose toujours que le prix des facteurs variables n'est pas affecté par la réforme. La quantité totale de travail est également fixée. La réforme se traduit donc par des variations des prix des produits 1 et 2 , des aides sur les surfaces allouées à ces deux cultures, et des surfaces consacrées à ces deux cultures. Par différentiation totale de (19), on a alors :

(20) $\pi_{L p}^{1} d p_{1}+\pi_{L L}^{1} d L_{1}+d a_{1}=\pi_{L p}^{2} d p_{2}+\pi_{L L}^{2} d L_{2}+d a_{2}$ 
La prise en compte de la contrainte globale au niveau de la surface totale $\left(d L=d L_{1}+d L_{2}=-G\right)$ permet d'écrire la statique comparative de la surface consacrée à la première culture de la façon suivante ${ }^{14}$ :

$$
\text { (21) } d L_{I}=\left(\pi_{L L}^{1}+\pi_{L L}^{2}\right)^{-1}\left(-\pi_{L L}^{2} G-\pi_{L p}^{1} d p_{1}+\pi_{L p}^{2} d p_{2}+d a_{2}-d a_{1}\right)
$$

La concavité de la fonction de profit restreint par rapport aux quantités des facteurs fixes $\left(\pi_{L L}^{1}<0, \pi_{L L}^{2}<0\right)$ et l'hypothèse de non infériorité de l'input terre $\left(\pi_{L p}>0\right)$ permettent de signer les effets du gel et des aides. Le gel fait décroître la surface consacrée à la culture $1^{15}$; la baisse du prix du produit 1 diminue la surface allouée à la première culture, mais la baisse du prix du produit 2 augmente cette surface ; enfin, l'aide à l'hectare versée à la culture 1 fait croître les surfaces qui lui sont consacrées, mais l'aide à l'hectare sur la culture 2 fait diminuer cette surface.

Dans le contexte de la réforme, la situation initiale pourrait - en première approximation, si les aides compensent exactement les effets des baisses des prix sur les rendements marginaux en valeur - être représentée par le point $A$ sur le graphique 4.1. La différentielle d'aide entre oléagineux et céréales (ou entre cultures irriguées et cultures non irriguées) aurait pour objectif d'éviter une baisse proportionnellement plus importante pour la culture 1 (oléagineux ou maïs irrigué) que pour la seconde culture (céréales ou maïs non irrigué). Même s'il est facile de comprendre les raisons historiques et d'intérêt sous jacentes, la logique économique de ce montage des aides, qui doit être appréciée dans le cadre général du complexe animal-végétal, n'est pas évidente.

Les effets liés au gel sont illustrés par le graphique 4.2. La réduction de la terre cultivée du montant du gel $\mathrm{G}$ se traduit par un déplacement de l'origine de $\mathrm{O}_{2}$ en $\mathrm{O}_{2}^{\prime}$ (la longueur $\mathrm{O}_{2} \mathrm{O}_{2}^{\prime}$ est égale au gel $G$ ). Compte tenu des aides compensatrices allouées aux deux produits, l'équilibre de répartition des surfaces se situe alors au point $C$ où l'expression (19) est vérifiée sous la contrainte $L_{1}+L_{2}=L-G$. En ce point, les valeurs de la terre sont égales pour les deux cultures. Les surfaces consacrées aux deux cultures sont égales à $O_{1} M_{2}$ et $O_{2}^{\prime} M_{2}$, respectivement. Comme dans le cas mono-produit, le gel entraîne une augmentation des prix virtuels de la terre, de $M_{1} E$ à $K S$ pour la culture 2 et de $M_{1} F$ à $M_{2} T$ pour la culture 1 .

\section{(insérer Graphique 4.2)}

Les aides compensatrices font donc que l'équilibre des allocations passe du point $B$ au point $A$, ce qui correspond à un accroissement de la surface consacrée à la culture proportionnellement la plus subventionnée $\left(a_{1}>a_{2}\right)$. Le gel des terres réduit, sur cet exemple, les deux soles cultivées, de la longueur $M_{1} M_{2}$ pour la première culture et de la longueur $M_{1} K$ pour la seconde. II est intéressant de

14 L'attention est centrée sur la surface allouée à la première culture. On obtient une équation similaire pour la surface consacrée à la seconde culture.

15 Le gel global fait également décroître la surface consacrée à la seconde culture. 
noter que la répartition du gel entre les deux cultures de dépend pas des aides compensatrices (cf. équation (21)), mais du seul rapport des pentes des rendements marginaux en valeur des surfaces.

En résumé, la baisse du prix de la culture 1 fait chuter la surface $L_{1}$ consacrée à la première culture, mais celle du produit 2 joue en sens inverse. Le versement de l'aide sur la culture 1 fait augmenter cette surface $L_{1}$, mais l'aide sur le produit 2 a un effet opposé. Une condition de neutralité des aides (en négligeant leur conditionnalité au gel) est alors :

(22) $\pi_{L p}^{1} d p_{1}+d a_{1}=\pi_{L p}^{2} d p_{2}+d a_{2}$

L'équation (22) peut être interprétée de deux façons, selon que la situation de référence est le marché libre ou la situation avant réforme.

Si la référence est le marché libre, sans soutien $\left(d p_{1}=d p_{2}=0\right)$, alors les aides sont neutres si elles sont égales pour les différentes cultures. On dira alors que les versements compensatoires sont réellement équivalents à des aides découplées. Dans le cadre de la réforme, ce n'est pas le cas.

Si la référence est la situation avant réforme, les aides sont neutres quant à leurs effets sur l'allocation des surfaces cultivées ex-ante si elles compensent exactement les baisses des prix. C'est à peu près le cas de la réforme de la PAC. Néanmoins, les aides étant conditionnelles au gel, celui-ci va, de toutes façons, affecter les surfaces cultivées en fonction des pentes des productivités marginales en valeur des terres cultivées.

L'impact des mesures de la réforme sur les volumes de production est moins clair (au sens de la neutralité) puisqu'il intègre, en outre, l'effet direct d'extensification direct dû à la baisse du prix de soutien du produit :

$$
\begin{aligned}
d y_{1} & =\pi_{p p}^{1} d p_{1}+\pi_{p L}^{1} d L_{1} \\
& =\pi_{p p}^{1} d p_{1}+\pi_{p L}^{1}\left(\pi_{L L}^{1}+\pi_{L L}^{2}\right)^{-1}\left(-\pi_{L L}^{2} G-\pi_{L p}^{1} d p_{1}+\pi_{L p}^{2} d p_{2}+d a_{2}-d a_{1}\right)
\end{aligned}
$$

Même si les aides sont neutres au sens de (22), la production sera affectée négativement par l'extensification des facteurs variables (terme $\pi_{p p}^{\prime} d p$, dans (23)) et par le gel des terres.

Du point de vue de l'efficacité économique, la nouvelle instrumentation basée sur les aides et le gel induit une charge morte qui peut être importante. Elle comprend d'abord l'aire BTR qui correspond au "surcoût" en ressources lié à l'extension de la culture la plus aidée par rapport à l'optimum $B$ et l'aire $K M_{2} R S$ qui correspond à la valeur de la deuxième culture perdue à cause du gel. Cette perte est supérieure au rectangle $K M_{2} M N$, produit de la surface gelée par le rendement en valeur $\left(M_{2} M=K N=M_{0} B\right)$ des terres marginales à l'optimum $B$, car le gel accroît le prix virtuel des terres inframarginales. A ces pertes directes, il faudrait ajouter le coût d'entretien de la jachère, les coûts d'administration du système d'intervention et les coûts de distorsion liés au prélèvement fiscal de 
financement des aides. Si l'objectif de la nouvelle instrumentation est seulement de réduire les quantités produites pour satisfaire aux engagements du GATT en termes de diminution des exportations subventionnées, le "prix à payer" peut s'avérer très élevé. La prise en compte des aménités-externalités liées aux différents usages de la terre va accentuer encore les inconvénients de cette nouvelle instrumentation.

\section{ii) prise en compte des externalités négatives et positives}

Le cadre multi-produits présenté ci-dessus peut être utilisé dans une perspective plus générale en intégrant les externalités, positives et négatives, liées à l'activité agricole. Afin de simplifier la présentation, nous supposons qu'il n'y a que deux usages de la terre. Le premier correspond à une grande culture (céréales) et génère des externalités négatives croissantes avec l'intensification. Le second correspond à une culture extensive sur des prairies permanentes et génère des externalités positives. De plus, nous supposons toujours que la technologie est non jointe dans les quantités de facteurs de façon à écrire le programme de court terme du producteur comme :

(24) $\pi^{r}\left(p_{1}, p_{2}, w, L_{1}, L_{2}, N\right)=\sum_{i=1}^{2} \pi^{i}\left(p_{i}, w, L_{i}, N\right)$

En l'absence de toute intervention publique, les allocations privées optimales des surfaces sont définies par les conditions du premier ordre suivantes :

(25) $\pi_{L}^{1}\left(p_{1}^{w}, w, L_{1}, N\right)=\lambda^{e}=\pi_{L}^{2}\left(p_{2}^{w}, w, L_{2}, N\right)$

où $p_{i}^{\prime \prime}$ désigne le prix non soutenu du produit $i$.

L'optimum privé se situe alors au point $A$ sur le graphique 4.3. Les allocations privées optimales des surfaces sont alors $L_{l}^{e}$ et $L_{2}^{e}$, et le prix (virtuel) de la terre est égal à $\lambda^{e}$. Si la première culture est à l'origine d'externalités négatives, d'autant plus importantes que les pratiques culturales sont intensives, et si la seconde culture est source d'externalités positives, l'optimum collectif (toujours sans soutien des prix de la grande culture) va se situer au point $C$ qui correspond aux allocations $L_{l}^{c}$ et $L_{2}^{c}$. En notant $D^{l}\left(p_{l}, w, L_{l}, N\right)$ la fonction de dommages liée au premier usage de la terre et $A^{2}\left(p_{2}, w, L_{2}, N\right)$ la fonction d'aménités associée au second usage, les conditions du premier ordre qui déterminent cet optimum social sont:

$$
\text { (26) } \pi_{L}^{1}\left(p_{1}^{w}, w, L_{1}, N\right)-D_{L}^{1}\left(p_{1}^{w}, w, L_{1}, N\right)=\lambda^{c}=\pi_{L}^{2}\left(p_{2}^{w}, w, L_{2}, N\right)+A_{L}^{2}\left(p_{2}^{w}, w, L_{2}, N\right)
$$

La condition (26) montre qu'à l'optimum public, l'écart entre les productivités marginales des terres affectées aux cultures 1 et 2 est égal à la somme du dommage marginal lié à la première culture et de l'aménité marginale associée à la seconde culture. 
Nous nous plaçons maintenant dans le cadre de la PAC "pré-réformée". Le soutien des prix de la grande culture nous amène alors au point $P$. Par rapport à l'optimum collectif $C$, les surfaces allouées à la production soutenue augmentent de $L_{l}^{c}$ à $L_{l}^{p}$ et les surfaces allouées à la culture extensive non soutenue diminuent de $L_{2}^{c}$ à $L_{2}^{p}$. Il est clair que le soutien des prix et la non prise en compte des externalités positives et négatives conduisent tous deux à accroître les surfaces allouées à la grande culture et à diminuer les surfaces en prairies permanentes (retournement des prairies).

\section{(insérer Graphique 4.3)}

Dans le cadre de la PAC réformée, les conditions du premier ordre qui déterminent l'allocation privée optimale des surfaces sont données par (19), conditions qui tiennent compte des aides compensatrices. Supposons, pour simplifier, que l'aide sur les hectares cultivées compense exactement la baisse du prix de la grande culture (i.e., $\partial \pi^{\prime} / \partial p_{1}=-a_{l}$ ) et que l'aide sur la seconde culture soit nulle $\left(a_{2}=0\right)$. Dans le cas où l'agriculteur n'a pas d'obligation de gel (cas d'un petit producteur), l'optimum privé se situe donc toujours au point $P$ sur le graphique 4.4. Ce point est toujours socialement sous optimal. Dans le cas où l'agriculteur gèle une partie de ses terres (cas d'un producteur professionnel), la surface cultivée allouée à la grande culture est $L_{l}^{r}$, i.e., $L_{l}^{P}-G$ (le gel est appliqué uniquement sur la grande culture). Il y a encore sous-optimalité collective de l'optimum privé car les effets externes, négatifs et positifs, ne sont pas pris en compte par le producteur et parce que la correction partielle de la première distorsion (baisse des prix de soutien de la première culture) est "annulée" par l'introduction de versements compensatoires liés aux hectares cultivés. De plus, le gel maintient une pression foncière qui empêche le retour des terres à la prairie permanente.

\section{(insérer Graphique 4.4)}

Sur la base du graphique 4.4, il est facile de vérifier que la seule correction de la distorsion sur les prix ne suffit pas pour atteindre l'optimum de premier rang en raison de la non prise en compte des dommages liés à la première culture et des aménités associées à la seconde production. Le lien entre les aides compensatrices de la réforme et les surfaces conduit à s'éloigner encore plus de cet optimum social (cf. équations (19) et (26)). En l'absence d'autres justifications, une politique optimale serait de supprimer l'écart entre le prix intérieur et le prix mondial, de taxer les externalités ${ }^{16}$ négatives d'un montant égal aux dommages et de subventionner la seconde culture à concurrence des aménités créées, de façon à retrouver les conditions du premier ordre optimales pour la collectivité (25) et de se ramener au point $C$. Les aides compensatrices n'auraient pas d'effet de distorsion, du moins dans le cadre de la théorie de la firme où le facteur travail est supposé fixe, si elles étaient versées sous forme d'aides directes sans lien avec l'usage du facteur terre. Une politique d'aides compensatrices transitoires basées sur une situation passée (aides compensatrices réellement découplées) et d'aides

16 Ces externalités étant liées aux techniques plus qu'au produit lui même, la base de taxation éventuelle devrait être les intrants générateurs de nuisances. 
permanentes à l'hectare sur la culture à l'origine d'effets externes positifs (aides rémunératrices couplées) permettrait déjà, dans le cadre de la réforme actuelle, de se rapprocher de cet optimum collectif en se situant au point $K$. A cet égard, il est clair que les compléments de primes liées aux faibles chargements de bétail à l'hectare et la prime à l'herbe vont dans le bon sens.

\section{Enseignements pour la Politique Agricole Commune}

L'approche analytique présentée dans les deux sections précédentes a permis de préciser les effets des trois principales mesures de la réforme de la PAC (baisse des prix des produits, gel des terres et aides compensatrices) sur, i) l'offre des produits et l'emploi des facteurs variables, ii) l'intensification, iii) les rémunérations des facteurs supposés fixes, travail familial et terre et, iv) l'efficacité allocative des nouvelles incitations. Sur la base de cette analyse, il est possible de dégager quelques enseignements généraux pour la Politique Agricole de la Communauté et de proposer certains aménagements souhaitables dans une perspective de plus long terme.

\section{i) les aides directes ne sont jamais totalement neutres}

Dans le cadre de la théorie de la firme mono-produit et en considérant que le travail agricole et la terre disponible sont fixes, nous avons montré que les aides compensatrices de la PAC réformée n'avaient pas d'impact sur l'offre du produit et la demande dérivée des facteurs, et donc sur les niveaux d'intensification. En ce sens, elles peuvent donc être considérées comme "découplées" (c'està-dire "déconnectées" des décisions d'offre et de demande dérivée). Néanmoins, dans le cadre de la firme multi-produits, les aides compensatrices de la réforme ont un impact sur le comportement d'offre via l'allocation des surfaces.

Dans le cas de plusieurs cultures, des aides compensatrices n'auront pas d'effet sur l'offre ${ }^{17}$, i) si elles n'influencent pas l'allocation des surfaces et, ii) si, pour une allocation des terres donnée, elles n'interviennent pas sur le niveau d'intensification (elles ne sont alors, pour le producteur, qu'un revenu extérieur forfaitaire). La première condition est satisfaite si les aides compensatrices sont déconnectées des surfaces ou, dans le cas d'un lien, si elles sont identiques pour toutes les cultures. Ceci n'est pas le cas dans le cadre de la réforme de mai 1992. La seconde condition est, par contre, satisfaite dans le cadre de la réforme de la PAC car les aides sont basées sur les rendements passés moyens (régionaux) et non sur les rendements, courants ou futurs, individuels. Ce critère conduit le producteur rationnel à baser ses décisions d'offre et de demande sur les prix de marché des produits et non sur la somme des prix et des aides à la tonne.

17 Par rapport à une référence où les diverses cultures bénéficient d'une même protection nominale, positive ou nulle. Il est clair que les aides actuelles sont plutôt conçues pour maintenir la répartition antérieure de la surface totale entre céréales et oléoprotéagineux. 
L'analyse précédente suggère qu'il est en principe possible de définir des aides compensatrices parfaitement neutres dans le cas où la quantité de travail est donnée. Ceci est impossible dans le cadre du ménage agricole, producteur et consommateur, où l'offre de travail est variable, car les aides auront toujours un impact sur les offres et les demandes dérivées par un effet revenu. II est possible de montrer qu'une augmentation du montant des aides considérées comme "découplées" dans le cadre de la théorie de la firme conduit, dans le cadre de la théorie du ménage, à i) une réduction du niveau du travail agricole, de l'offre et de la demande des facteurs variables et, ii) un accroissement du temps de loisir (diminution du temps de travail total), du revenu total du ménage et du niveau de bien-être (cf., par exemple, Nakajima, 1986, p. 41 et suivantes, pour une analyse générale, et Benjamin et Guyomard, 1993, pour une application au cas particulier de la PAC).

En résumé, les aides compensatrices (sur les surfaces cultivées) de la réforme de la PAC ne sont que très partiellement découplées. Elles ont un double impact sur l'offre des diverses grandes cultures, via l'allocation des surfaces et via l'effet revenu (arbitrage travail - loisir). Dans le cas des productions animales, les aides sont basées sur les effectifs et leur découplage est donc également partiel.

ii) la réforme devrait modifier la répartition factorielle des revenus, au profit du foncier et au détriment du travail

La réforme de la PAC devrait conduire à une diminution de la rémunération du facteur terre (voire à une augmentation) moindre que celle de la rémunération du facteur travail. Ce résultat est la conséquence directe du lien des aides aux surfaces. Les aides ciblées apparaissent donc plus comme un instrument de protection et de soutien des valeurs patrimoniales du secteur agricole que comme un instrument de soutien du revenu du travail agricole proprement dit. En d'autres termes, elles favorisent la rémunération du facteur foncier, spécifique au secteur et immobile, au détriment du facteur travail, non spécifique et mobile. II est clair que ce résultat est en contradiction avec les objectifs déclarés de la PAC et des promoteurs de la réforme ${ }^{18}$.

Les aides compensatrices de la réforme sont ciblées sur la terre et vont donc favoriser les propriétaires fonciers et les titulaires des droits aux primes. Des aides directes liées non plus aux surfaces mais à la quantité de travail permettraient de renverser ces effets, c'est-à-dire d'accroître la rémunération du travail par rapport à celle de la terre (cf. équations (15a) et (15b)).

iii) la réforme devrait conduire à une moindre intensification, mais le gel des terres va freiner ce mouvement

18 Il est clair en particulier que les aides ne bénéficiant pas aux employés salariés du secteur, alors que les aides aux cultures peuvent bénéficier en partie à leurs propriétaires. 
La réforme devrait aboutir à une moindre intensification, sur l'ensemble des surfaces et également sur les surfaces effectivement cultivées. Cependant, le gel des surfaces va freiner cette incitation à des pratiques culturales moins intensives. Plus le gel sera important, plus l'extensification sera réduite. Le gel apparaît donc comme contraire à l'un des principes de base de la réforme qui est le retour à des pratiques culturales moins intensives et plus respectueuses de l'environnement. Le gel va en outre retirer de la production des terres de bonne qualité qui pourraient produire sans subventions, d'où une perte pour la collectivité.

iv) quelle rationalité pour le gel des terres?

La terre est un facteur de production spécifique au secteur agricole, immobile et limité en quantité au niveau de la branche par la surface totale disponible. Quel argument peut alors justifier, d'un point de vue économique, le gel d'une partie des surfaces?

Le recours à cet instrument est généralement motivé par l'objectif de réduction de la production agricole communautaire. Mais le principal problème de la Communauté n'est pas de produire trop de céréales par rapport à une demande intérieure, mais de soutenir les prix intérieurs à des niveaux supérieurs aux prix mondiaux, ce qui nécessite le recours à des subventions aux exportations pour écouler les surplus, produits à un coût trop élevé, sur les marchés tiers.

Si l'objectif premier du gel est la réduction des volumes produits, le décideur public devrait chercher à minimiser le coût de production d'un volume donné. Or le gel de la réforme renchérit le coût d'opportunité de la terre et contribue donc à amoindrir la compétitivité de l'agriculture communautaire.

Il est vrai que le gel des surfaces, en réduisant l'offre intérieure, devrait limiter les volumes exportés avec subventions. II va donc faciliter le respect des engagements acceptés dans le cadre de l'accord final au GATT. Mais le prix - en termes de gaspillage de ressources - à payer pour maintenir le prix d'intervention au dessus du cours mondial est élevé.

En cas de dépassement de la quantité autorisée, l'instrument le plus facile à utiliser, dans le cadre de la réforme actuelle avec un prix intérieur toujours supérieur au cours mondial, est un accroissement du taux de gel. Les effets négatifs du gel analysés dans les sections précédentes en seraient aggravés : frein à l'extensification, augmentation des coûts de production et du prix des terres, augmentation de la rémunération des propriétaires fonciers au détriment de la rémunération du travail et obération de la compétitivité internationale du secteur communautaire des grandes cultures.

Une des principales limites de la réforme de la PAC, dans sa version de mai 1992 et pour le secteur des céréales, est de maintenir un prix intérieur supérieur au cours mondial. Les exportations sont toujours subventionnées, même si la subvention unitaire a été considérablement réduite par rapport à la situation pré-réformée. Le maintien d'un écart entre les prix intérieurs et mondiaux et le gel des terres obèrent la compétitivité internationale des céréales communautaires. L'alignement du prix 
intérieur sur le prix mondial permettrait de s'affranchir de toute contrainte à l'exportation au GATT (restitutions nulles) et rendrait l'usage du gel des terres caduque. Au total, il en résulterait une amélioration de la compétitivité des céréales communautaires, sur les marchés mondiaux par rapport à nos concurrents internationaux et sur le marché intérieur face aux produits de substitution des céréales.

La logique de la réforme, et en particulier de la position Française, est de placer la priorité sur la stabilisation des revenus en maintenant un "reliquat" de soutien par les prix au détriment de la compétitivité. Mais les aides compensatrices à l'hectare apportent déjà un confortable "matelas" de sécurité pour la stabilisation des revenus. Un rapprochement systématique des prix de soutien intérieurs et des cours mondiaux permettrait à l'Union Européenne de réserver son enveloppe de restitutions pour contrer, de façon uniquement stratégique, le programme américain d'encouragement aux exportations (EEP ou Export Enhancement Program). Ce dernier perdrait ainsi toute légitimité en raison de la symétrie entre les politiques agricoles de part et d'autre de l'Atlantique.

Une première étape dans cette direction serait d'établir un double marché des céréales où les terres actuellement gelées seraient remises en culture, mais la production sur ces dernières serait rémunérée strictement en fonction du prix à l'exportation. Une telle évolution ne serait pas contraire aux principes du GATT puisque les quantités seraient exportées sans subventions. Elle éviterait, en outre, la charge budgétaire correspondant au gel des terres.

v) les incitations à la jachère écologique sont très faibles et la prise en compte des aménités est pratiquement nulle ${ }^{19}$

Le gel des terres analysé ci-dessus, gel imposé pour des motifs de contrôle de l'offre, ne doit pas être confondu avec un gel dicté par des considérations de préservation des ressources et de l'environnement, c'est-à-dire la jachère écologique.

L'une des critiques majeures que l'on peut faire à la réforme de la PAC est que le gel répond à une logique de réduction des surplus exportables, ces derniers étant une conséquence directe des incitations erronées du passé. Le gel devrait, au contraire, être l'occasion de promouvoir les fonctions de l'agriculture à l'égard de la conservation de l'espace et des ressources. Les terres non cultivées allouées aux prairies naturelles, les zones "tampon" des vallées, les zones boisées, etc. sont créatrices d'aménités liées au paysage et à la bio-diversité. Ces effets externes positifs de l'agriculture ne sont pas suffisamment reconnus et pris en compte dans la réforme ${ }^{20}$. Ce sont des biens publics, mal valorisés, pas ou très peu subventionnés et sans groupes de défense bien organisés. De plus, les

19 Notons cependant que certaines mesures, timides, visent à encourager les externalités positives de l'activité agricole : primes pour l'entretien des friches, aides au reboisement et à la création de biotopes, ...

20 Ils révèlent, en tout cas, la contradiction entre le coeur de la réforme centré sur les grandes cultures et le volet agro-forestier qui est, pour l'essentiel, resté au stade des intentions. 
subventions allouées aux cultures incitent au maintien en terres arables de surfaces qui pourraient et devraient retourner à la prairie ou à la jachère écologique.

La jachère écologique est donc non seulement dépourvue d'encouragements, mais aussi pénalisée par les aides aux surfaces cultivées qui sont les seules à bénéficier de subventions. II faudrait au moins étendre les versements à toutes les surfaces si l'objectif est de lier l'aide à l'occupation de l'espace rural ou, mieux, accorder des aides plus importantes pour les terres potentiellement susceptibles d'être placées en jachère écologique ${ }^{21}$.

\section{Conclusion}

La réforme de la PAC de mai 1992 comporte une réorientation profonde des modalités de soutien, les aides aux facteurs et aux structures de production remplaçant en grande partie les aides aux produits. Néanmoins, ce changement est conduit dans le cadre des Organisations Communes de Marché (OCM) existantes (avec en particulier, dans le cas des céréales, le maintien de prix intérieurs supérieurs aux cours mondiaux), ce qui porte en germe des risques d'inefficacité. Des aménagements à cette réforme devraient être guidés par les principes suivants.

a) Les aides compensatrices de la réforme sont destinées à compenser les pertes de revenu liées à la baisse des prix agricoles. Elles doivent donc être transitoires et dégressives dans le temps (la dégressivité pourrait être, par exemple, proportionnelle aux gains de productivité). II serait préférable de les verser sous forme de paiements directs basés sur une référence passée et de rompre le lien avec le foncier, en d'autres termes d'accroître leur caractéristique "découplée".

b) Les prix intérieurs des céréales devraient être alignés sur les cours mondiaux de façon à améliorer la compétitivité internationale des céréales communautaires, à annuler la "fausse" nécessité du gel des terres et à s'affranchir de la contrainte quantitative au GATT de réduction des exportations subventionnées. Une étape intermédiaire dans ce sens serait de mettre en oeuvre un double marché des céréales ce qui aurait, en outre, l'avantage d'une cohérence accrue avec les règles de fonctionnement de l'OCM oléagineux.

c) Enfin, il faudrait mettre en place un système d'aides directes qui rémunère les externalités positives (conservation des ressources) et encourage les pratiques culturales plus respectueuses de l'environnement. Ces aides "écologiques" devraient, au contraire des aides compensatrices, être explicitement couplées, permanentes, ciblées (c'est-à-dire liées à des objectifs d'entretien de la nature, de maintien de la bio-diversité, de développement rural et régional, etc. et basées sur un zonage des parcelles selon leurs fonctions potentielles).

21 De plus, si les aides ont pour objectif de contribuer au maintien du tissu rural des régions défavorisées, il existe une autre base de référence plus immédiate que celle des grandes cultures, essentiellement localisées dans les régions favorisées. 
La réforme de la PAC est un pas, significatif mais insuffisant, dans la direction d'une agriculture communautaire plus compétitive et plus respectueuse de l'environnement. Les aménagements proposés ci-dessus devraient permettre d'accroître encore plus cette compétitivité et d'encourager le rôle de l'agriculture dans la préservation de l'espace rural et de l'environnement. 


\section{Références bibliographiques}

Benjamin C., Guyomard H., 1993, L'offre de travail extérieur des femmes : impact de la réforme de la PAC. Société Française d'Economie Rurale, Montpellier.

Burrell A., 1993, The Role of Direct Income Support in Agricultural Policy Reform. In Direct Payments in Agricultural and Regional Policies, Lehmann B., Popp H. W. and Stucki E. (eds), Proceedings of the 30th EAAE Seminar, Hartung-Gorre Verlag, Konstanz.

Guyomard H., Vermersch D., 1989, La fonction de profit restreint : un outil d'analyse des politiques agricoles. Miméo INRA-ESR, Rennes.

Guyomard H., Mahé L.-P., 1993, Producer Behaviour under Strict Rationing and Quasi-Fixed Factors. Economic Development Center, University of Minnesota, Bulletin Number 93-2.

Haynes J., Buckwell A., Tangermann S., Mahé L.-P., 1992, The MacSharry Proposals: A Question of Efficiency. CEAS, Centre for European Agricultural Studies, Wye College, University of London.

Hulot J. F., 1993, Mise en oeuvre des paiements directs par la réforme de la Politique Agricole de la CEE. In Direct Payments in Agricultural and Regional Policies, Lehmann B., Popp H. W. and Stucki E. (eds), Proceedings of the 30th EAAE Seminar, Hartung-Gorre Verlag, Konstanz.

Josling T. E., Mariani A. C., 1991, The Distributional and Efficiency Implications of the Mac Sharry Proposals for Reform of the CAP. Working paper.

Kohli U. R., 1981, Nonjointness and Factor Intensity in US Production. International Economic Review, 22, 3-18.

Lau L. J., 1976, A Characterization of the Normalized Restricted Profit Function. Journal of Econometrics, 28, 256-268.

Mahé L.-P., Rainelli P., 1987, Impact des pratiques et des politiques agricoles sur l'environnement. Cahiers d'Economie et Sociologie Rurales, 4, 9-31.

Nakajima C., 1986, Subjective Equilibrium Theory of the Farm Household. Developments in Agricultural Economics, 3, Elsevier. 
Tableau 1. Effets de la réforme de la PAC sur la demande du facteur variable et sur l'intensification.

\begin{tabular}{|l|c|c|c|c|c|}
\hline & \multicolumn{2}{|c|}{$\begin{array}{c}\text { Baisse du prix du } \\
\text { produit }\end{array}$} & $\begin{array}{c}\text { Gel des } \\
\text { surfaces }\end{array}$ & $\begin{array}{c}\text { Aides } \\
\text { compensatrices }\end{array}$ & Total (1) \\
\cline { 2 - 3 } & $\begin{array}{c}\text { effet } \\
\text { direct }\end{array}$ & $\begin{array}{c}\text { effet } \\
\text { indirect }\end{array}$ & & & \\
\hline $\begin{array}{l}\text { Demande du facteur } \\
\text { variable }(x) \\
\text { terre et facteur } \\
\text { variable substituts } \\
\left(\pi_{\lambda w}<0\right)\end{array}$ & -- & - & + & 0 & - \\
- terre et facteur \\
$\begin{array}{l}\text { variable compléments } \\
\left(\pi_{\lambda w}>0\right)\end{array}$
\end{tabular}

(1) effet probable avec les paramètres actuels de la réforme. 
Graphique 1. Conséquences de la réforme de la PAC sur l'intensification (cas d'une technologie mono-produit).

Note. L'extensification globale est mesurée par la baisse de l'ordonnée de $x$; l'extensification sur les surfaces cultivées est mesurée par la pente des rayons $O A, O B, O C$ et $O D$.

Graphique 2. Variations de la valeur et du prix virtuel de la terre.

Graphique 3.1. Variation de la rémunération de la terre.

Graphique 3.2. Variation de la rémunération du travail familial.

Graphique 4.1. Impact des aides compensatrices de la réforme de la PAC sur l'allocation des surfaces.

Graphique 4.2. Impact combiné des aides compensatrices et du gel des terres de la réforme de la PAC sur l'allocation des surfaces.

Graphique 4.3. Détermination des allocations optimales des surfaces dans le cadre de la PAC préréformée.

Graphique 4.4. Détermination des allocations optimales des surfaces dans le cadre de la PAC réformée. 

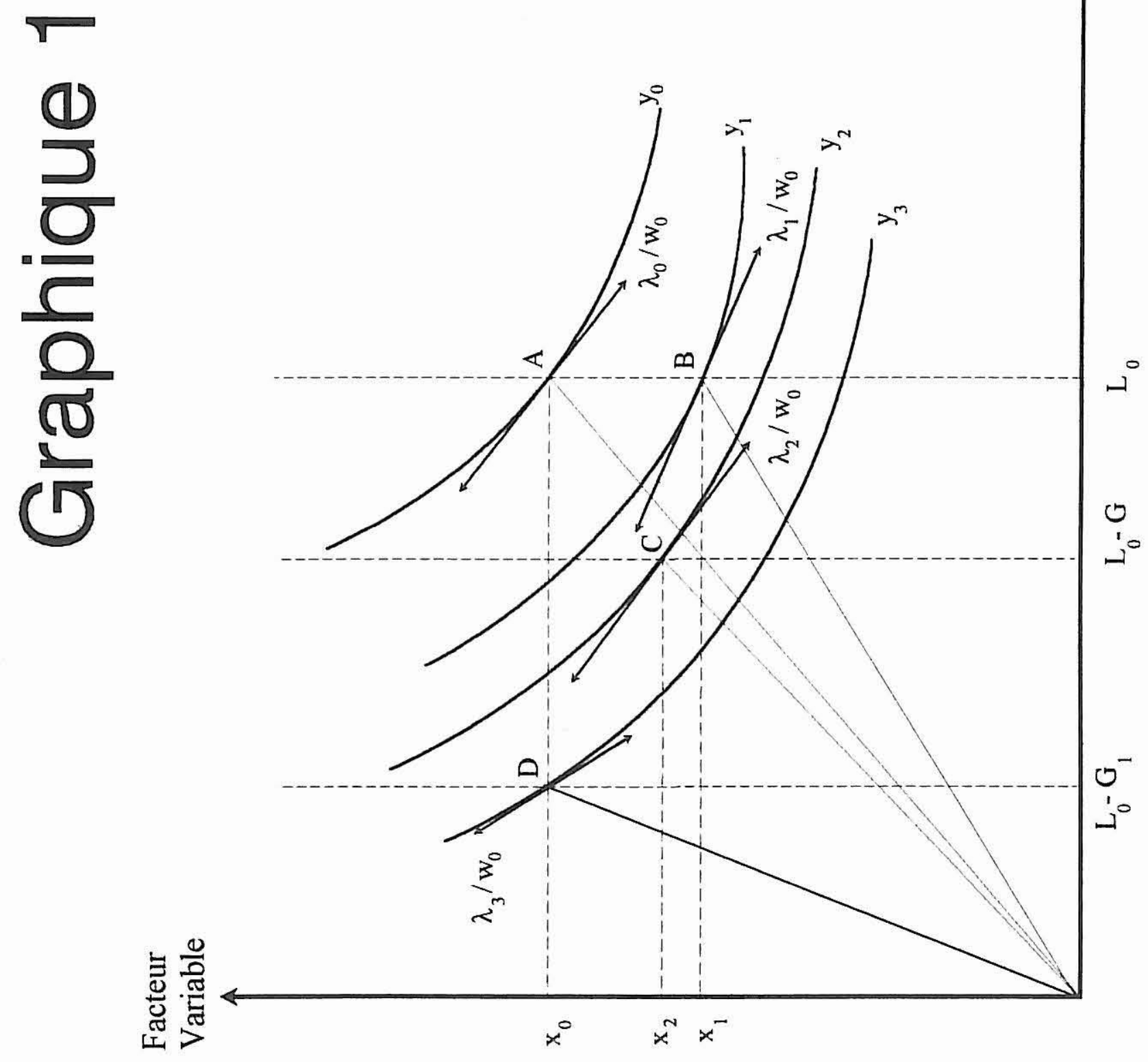


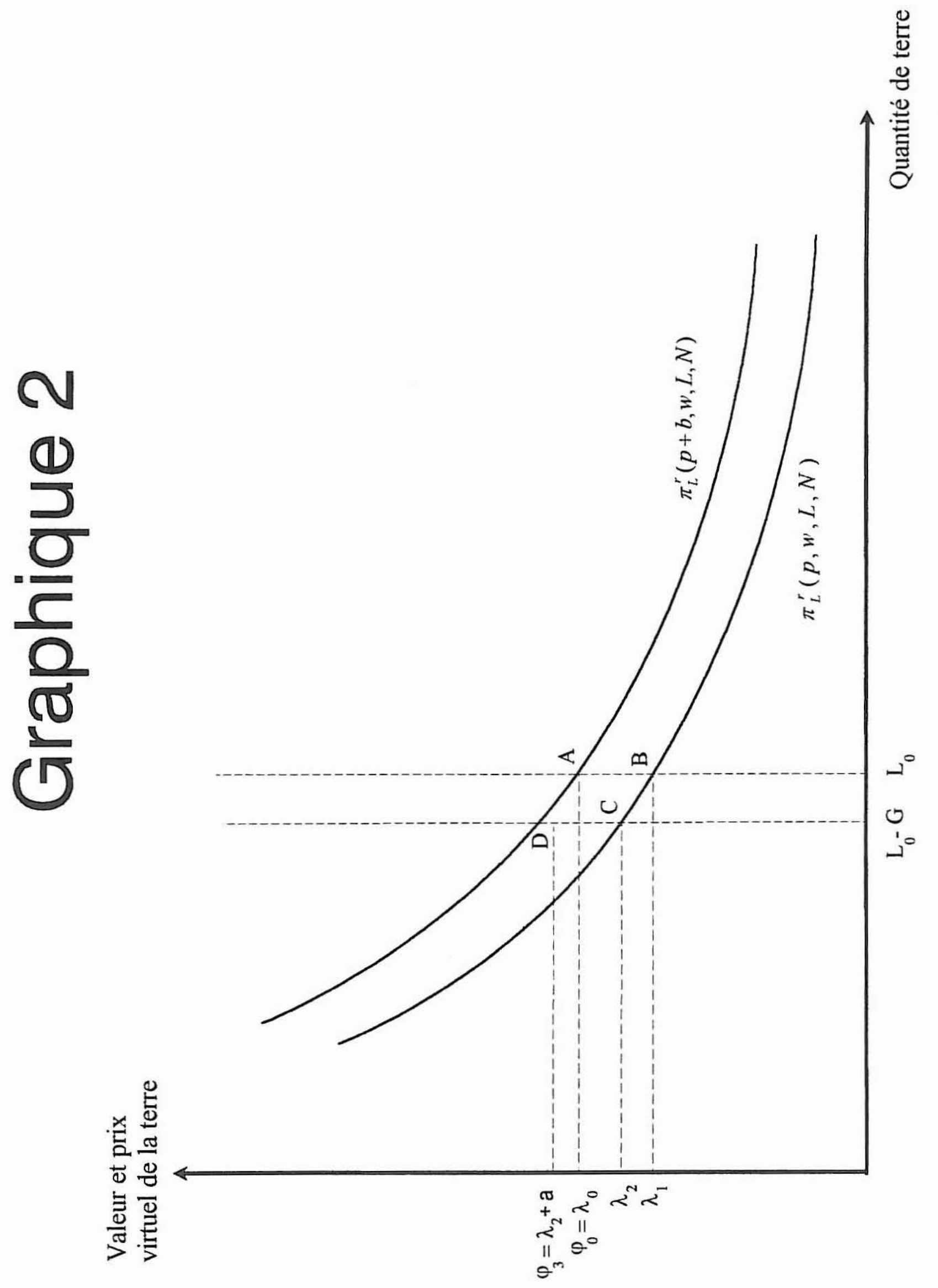




\section{Graphique 3.1}

Valeur et prix

virtuel de la terre

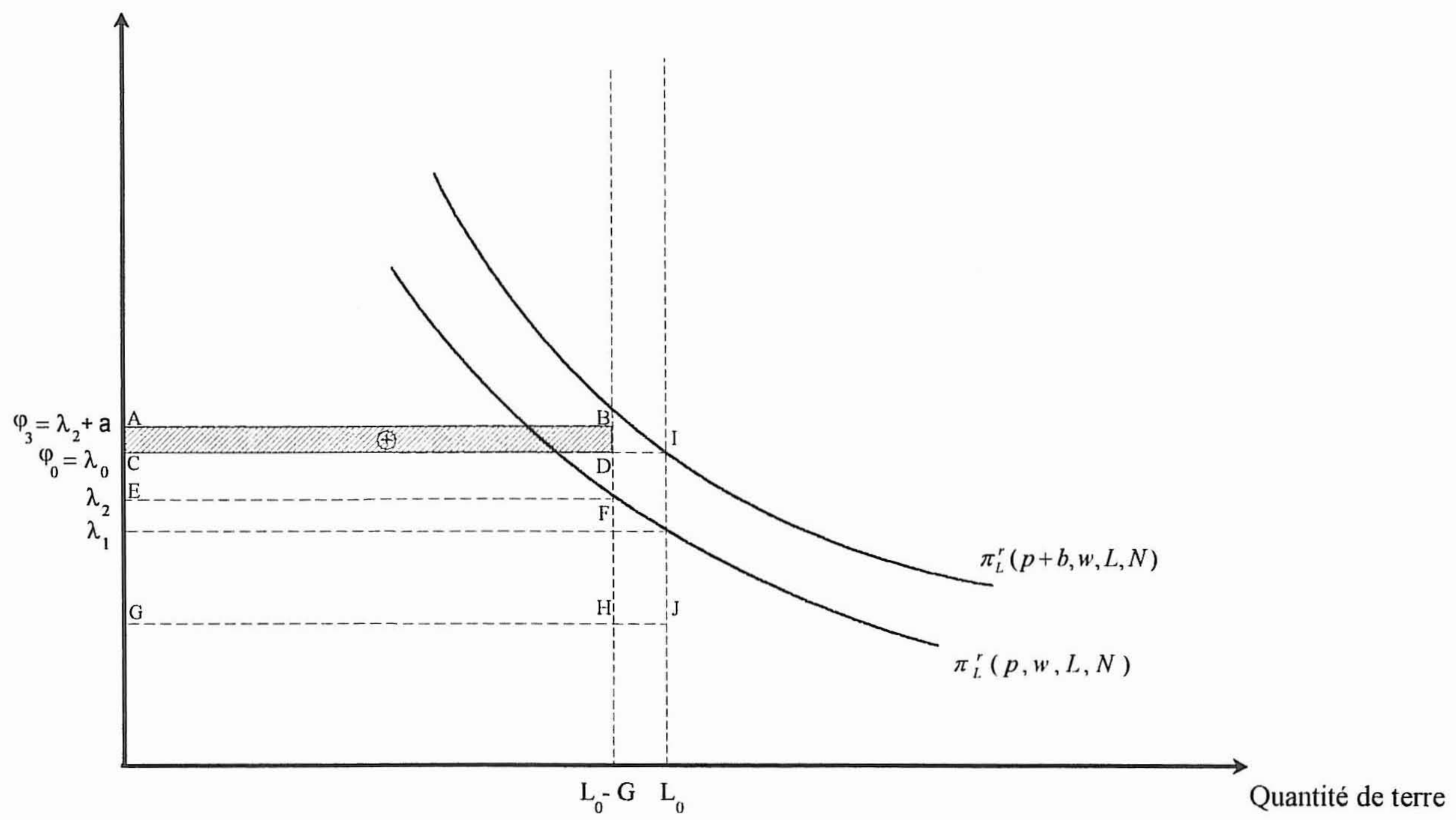




\section{Graphique 3.2}

Valeur et prix virtuel du travail familial

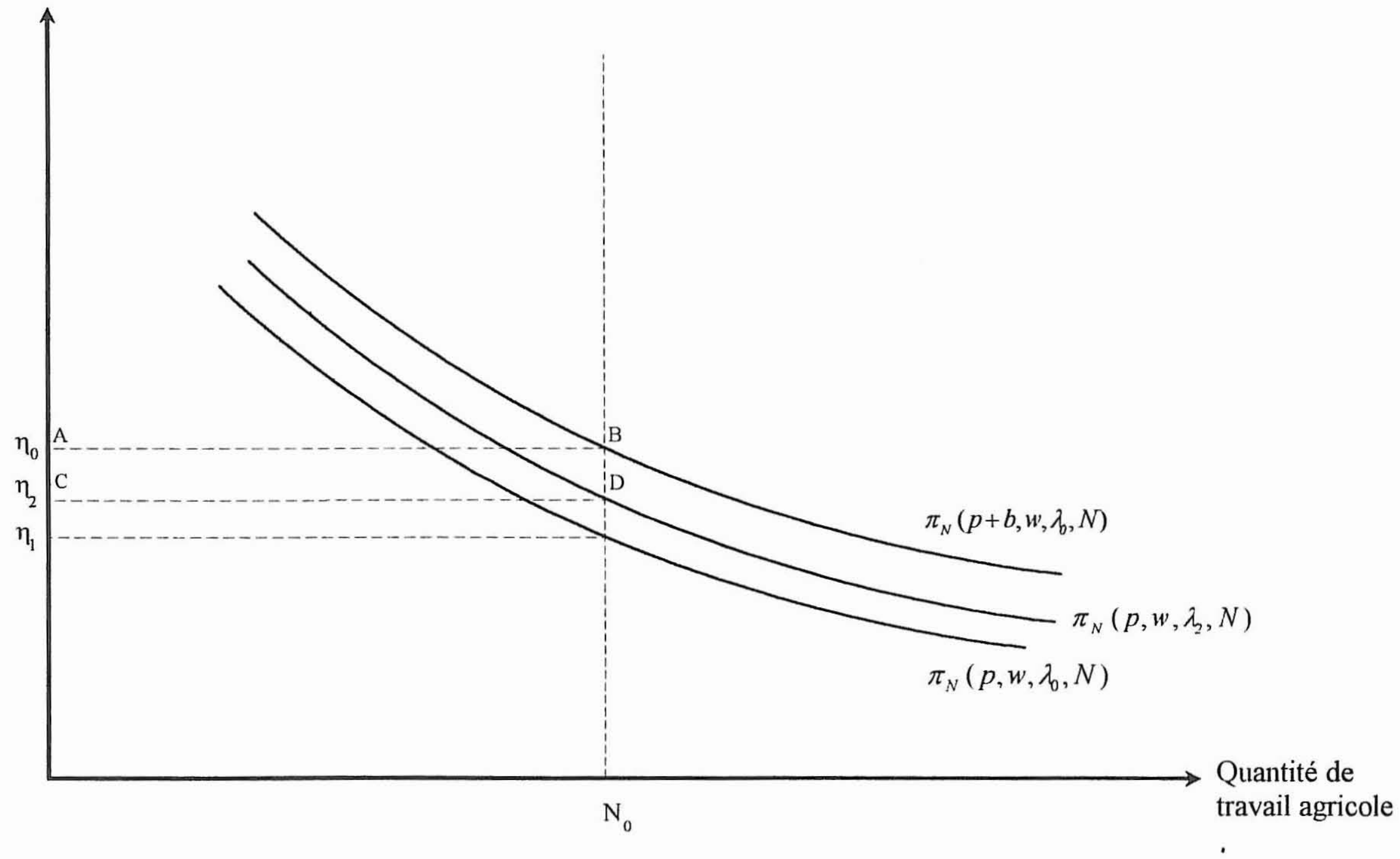




\section{Graphique 4.1}

Valeur et prix virtuel de la terre

Valeur et prix virtuel de la terre allouée à la culture 1

allouée à la culture 2

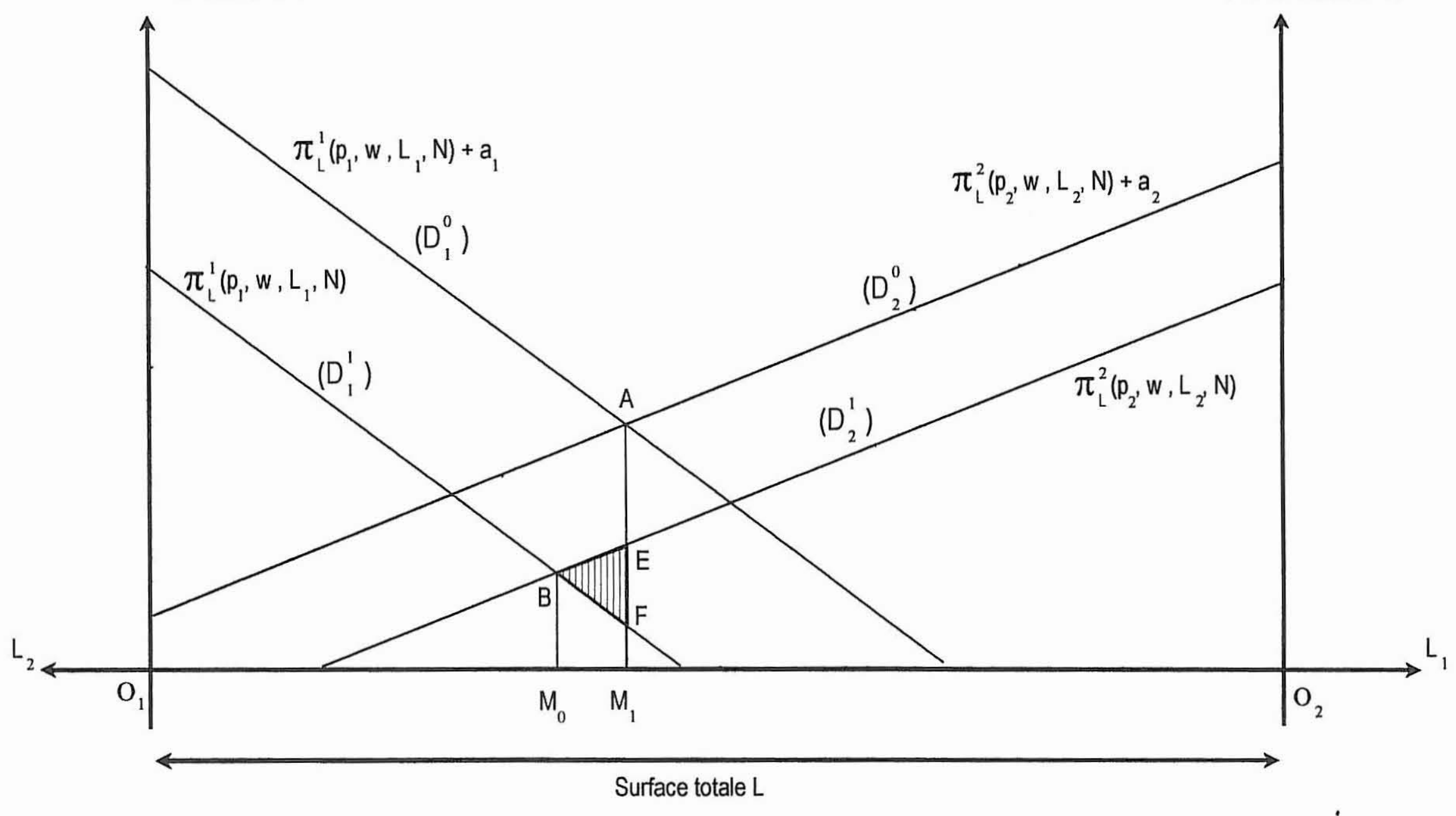




\section{Graphique 4.2}

Valeur et prix virtuel de la terre allouée à la culture 1

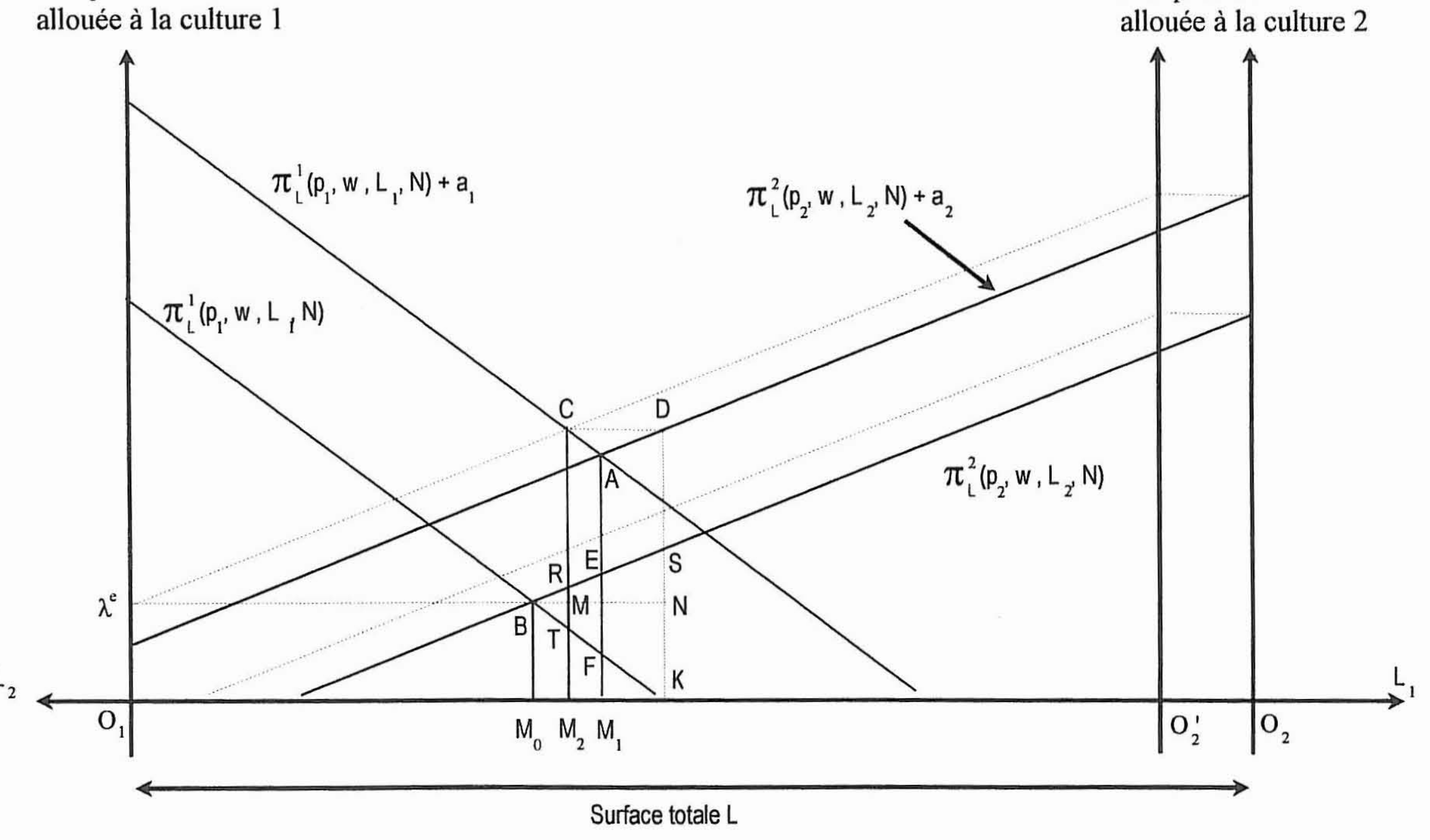


Valeur et prix virtuel de la terre allouée à la culture 1

\section{Graphique 4.3}

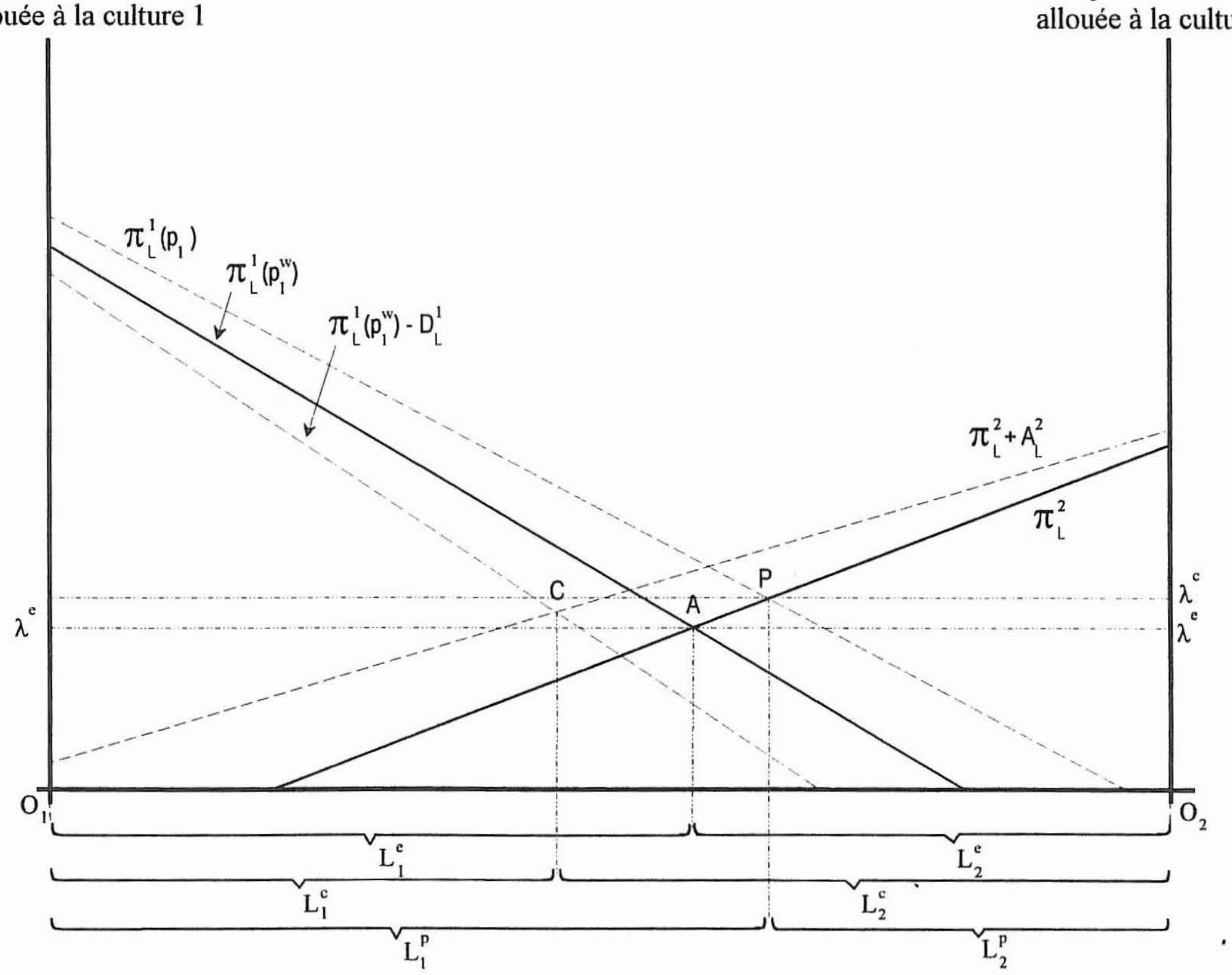




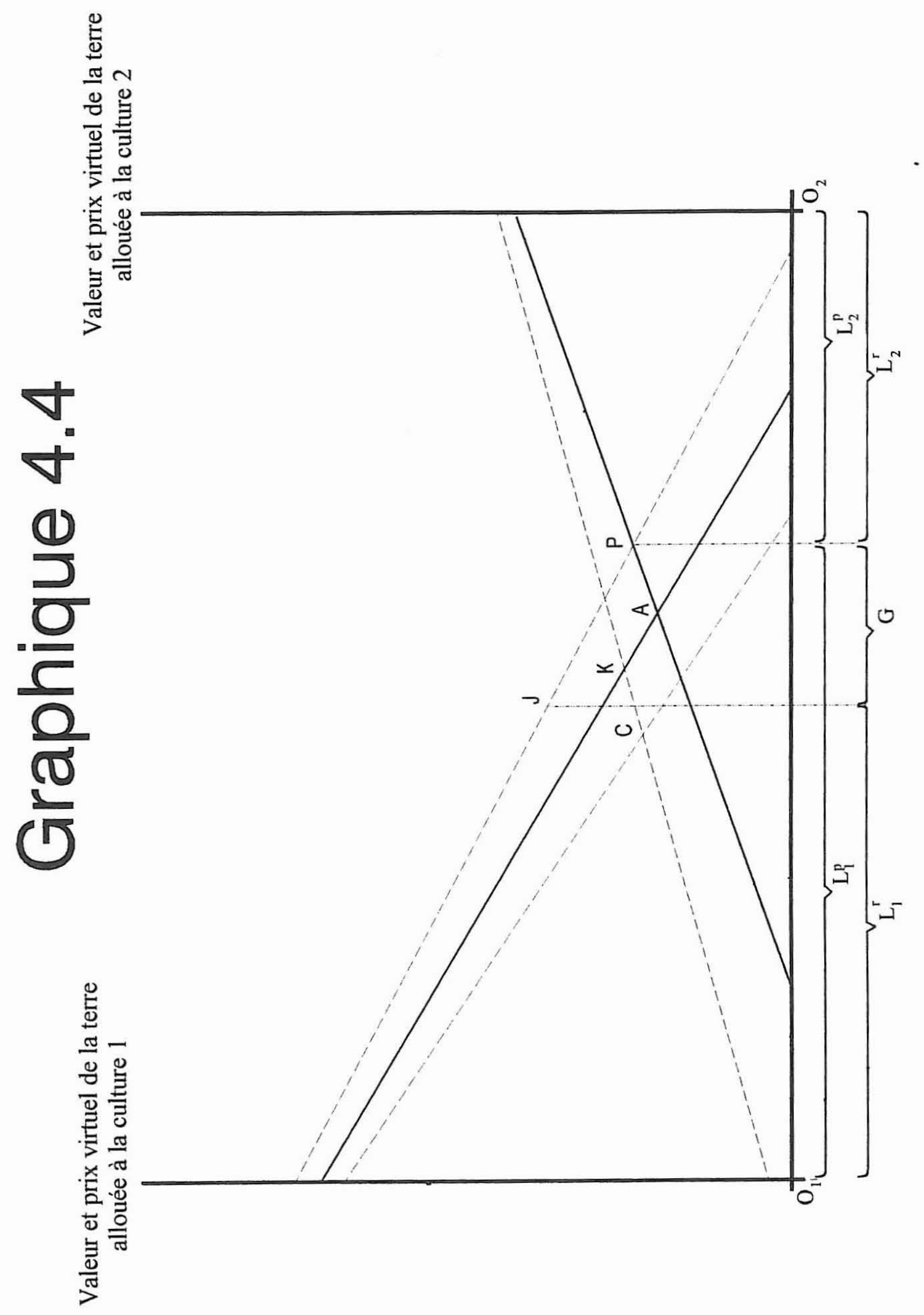


90-01 L'IMPACT DE LA PROPOSITION AMERICAINE AU GATT SUR LES AGRICULTURES DE LA CEE ET DES USA. Hervé GUYOMARD, Louis-P. MAHE, Christophe TAVERA (1990).

90-02 AGRICULTURE IN THE GATT : A QUANTITATIVE ASSESSMENT OF THE US 1989 PROPOSAL. Hervé GUYOMARD, Louis-P. MAHE, Christophe TAVERA (1990).

90-03 EC-US AGRICULTURAL TRADE RELATIONS : DO POLITICAL COMPROMISES EXIST ? Louis-P. MAHE, Terry L. ROE (1990).

90-04 ANALYSE MICRO-ECONOMIQUE DE L'EXPLOITATION AGRICOLE. Catherine BENJAMIN (1990).

90-05 PSE, AMS AND THE CREDIT FOR SUPPLY MANAGEMENT POLICIES IN THE GATT NEGOTIATIONS (application to the EC case). Hervé GUYOMARD, Louis-P. MAHE (1990).

90-06 COMPLETING THE EUROPEAN INTERNAL MARKET AND INDIRECT TAX HARMONIZATION IN THE AGRICULTURAL SECTOR. HeIvé GUYOMARD, Louis-P. MAHE (1990).

90-07 ALIMENTATION ANIMALE ET DYNAMIQUE DES PRIX DES MATIERES PREMIERES SUR LE MARCHE FRANCAIS. Yves DRONNE, Christophe TAVERA (1990).

91-01 ECONOMIC BEHAVIOUR OF AGRICULTURAL HOUSEHOLDS: IMPLICATIONS OF ASSUMING PERFECT SUBSTITUTABILITY BETWEEN LABOURS. Catherine BENJAMIN, Hervé GUYOMARD (1991).

91-02 LIMITATION DES IMPORTATIONS EUROPEENNES DE SUBSTITUTS DES CEREALES : IMPACT BUDGETAIRE ET DE BIEN-ETRE ECONOMIQUE. Chantal LE MOUEL (1991).

91-03 L'EVOLUTION DE LA POLITIQUE AGRICOLE COMMUNE ET SON IMPACT SUR LES PRODUCTIONS ET REGIONS AGRICOLES FRANCAISES. HeIvé GUYOMARD, Yves LEON (1991).

91-04 PUBLIC INPUTS, ALLOCATABLE FIXED FACTORS AND THE THEORY OF THE MULTIPRODUCT FIRM : A CLARIFICATION. Hervé GUYOMARD (1991).

91-05 LA REFORME DE LA PAC : Une révolution ou un grand pas dans la bonne direction? Hervé GUYOMARD, Louis-P. MAHE (1991).

92-01 LA POLITIQUE AGRICOLE COMMUNE DANS L'ETAU DE L'URUGUAY ROUND. HeIvé GUYOMARD, Louis-P. MAHE (1991).

92-02 TRADE COMPROMISES BETWEEN THE EC AND THE US : An Interest Group - Game Theory Approach. Martin JOHNSON, Louis-P. MAHE, Terry L. ROE (1992).

92-03 LE PROJET Mac SHARRY : facteurs de sensibilité du débouché céréalier communautaire. Hervé GUYOMARD, Louis-P. MAHE (1992).

92-04 JOINT DECISION IN LABOUR SUPPLY AND DEMAND BEHAVIOUR : AN ANALYSIS OF FRENCH AGRICULTURAL HOUSEHOLDS. Catherine BENJAMIN, Hervé GUYOMARD (1992).

92-05 MODELE DE TRANSMISSION DES PRIX GARANTIS DE CEREALES DANS LA COMMUNAUTE ECONOMIQUE EUROPENNE : DEVELOPPEMENTS THEORIQUES ET APPLICATION A LA FRANCE. Yves SURRY (1992). 
92-06 IMPORT TARIFFS, DOMESTIC DISTORTIONS AND "MARKET LINKAGES". Chantal LE MOUEL (1992).

93-01 CONSEQUENCES DE LA REFORME DE LA PAC SUR L'AGRICULTURE BRETONNE. Anne-Marie PELHERBE (1992).

93-02 LA REFORME DE LA PAC ET LES NEGOCIATIONS DU GATT - QUELLE COMPATIBILITE ? Hervé GUYOMARD, Louis-P. MAHE (juin 1992).

93-03 THE EC AND US AGRICULTURAL TRADE CONFLICT AND THE GATT ROUND : PETTY MULTILATERALISM ? Hervé GUYOMARD, Louis-P. MAHE, Terry L. ROE (1993).

93-04 DECISIONS DE TRAVAIL DES MENAGES AGRICOLES FRANCAIS. Catherine BENJAMIN, Alessandro CORSI, Hervé GUYOMARD (1993).

93-05 PSE AND DISTORTING AGGREGATE MEASURE OF SUPPORT IN THE CONTEXT OF PRODUCTION QUOTAS. Hervé GUYOMARD, Louis-P. MAHE (1993).

93-06 IS A PRODUCTION QUOTA PARETO SUPERIOR TO PRICE SUPPORT ONLY? HEIVÉ GUYOMARD, Louis-P. MAHE (1993).

93-07 PRODUCER BEHAVIOUR UNDER RATIONING WITH TRADABLE RIGHTS. HeIVé GUYOMARD, Louis-P. MAHE (1993).

93-08 CALCUL DES ELASTICITES PRIX ET REVENU SOUS HYPOTHESE DE BUDGETISATION PAR ETAPES : une méthode approchée. Alain CARPENTIER, Hervé GUYOMARD (1993).

94-01 LA REFORME DE LA PAC ET LES NEGOCIATIONS DU GATT. Perspectives pour l'agriculture française et communautaire. Hervé GUYOMARD, Louis-P. MAHE (1993).

94-02 L'OFFRE DE TRAVAIL DES FEMMES. Application à l'agriculture française. Catherine BENJAMIN, Hervé GUYOMARD et Michel SOLLOGOUB (1994).

94-03 LA NOUVELLE INSTRUMENTATION DE LA POLITIQUE AGRICOLE COMMUNE. Hervé GUYOMARD et Louis-P MAHE (1994). 